\title{
A Meta-Analysis of the Role of Trust in the Leadership- Performance Relationship
}

\author{
Alison Legood*1 ${ }^{1}$, Lisa van der Werff ${ }^{2}$, Allan Lee $^{1}$ and Deanne Den Hartog ${ }^{3}$ \\ ${ }^{1}$ University of Exeter \\ ${ }^{2}$ Irish Institute of Digital Business, Dublin City University \\ ${ }^{3}$ University of Amsterdam \\ *Corresponding author information: Alison Legood, Exeter University Business School, \\ University of Exeter, Exeter, EX4 4SB, UK (a.legood@exeter .ac.uk).
}

Please cite as:

Legood, A., van der Werff, L., Lee, A., \& Den Hartog, D. (2021). A meta-analysis of the role of trust in the leadership-performance relationship. European Journal of Work and Organizational Psychology, 30(1), 1-22. https://doi.org/10.1080/1359432X.2020.1819241 


\section{A Meta-Analysis of the Role of Trust in the Leadership - Performance Relationship}

Trust plays a critical role as a key mechanism through which the positive impact of leadership can be elicited. This meta-analysis examines the incremental validity of eight leadership styles (transformational, transactional, authentic, ethical, servant, abusive, paternalistic and empowering) in predicting affective and cognitive dimensions of trust as mediating mechanisms in the relationship between leadership and performance outcomes. To counter issues of common method variance, we focus on the impact these mediated relationships have on independently measured other ratings of outcomes; task performance and organisational citizenship behaviour (OCB). We also test whether trust in the leader differs from that of the broader construct of Leader-Member Exchange (LMX) quality. Using 185 independent studies conducted since 1988, we find that contemporary styles, particularly servant and ethical leadership, demonstrate incremental validity over transformational and transactional (contingent reward) leadership in predicting trust in the leader. Meta analytical mediation tests reveal that trust in the leader and LMX play unique roles in mediating the relationship between leadership styles and performance related outcomes. Finally, evidence suggests that affective and cognitive dimensions of trust play a differential role in this mediating process and that affective trust in the leader is a more powerful predictor of performance and OCB.

Keywords: Trust, leadership, performance, OCB, meta-analysis 


\section{Introduction}

Since the global financial crisis of 2007 , trust in business has fallen to record lows. For instance, public trust in CEOs has dropped to $31 \%$ in developed countries (Edelman Trust Barometer, 2016). Engendering trust has been a central tenet of different organisational leadership theories and robust relationships have been found between employees' trust in their leader and important outcomes (e.g., Ng, 2017; Podsakoff et al., 1990; Schaubroeck et al., 2011). Research, for example, consistently shows that the trust which exists between a leader and a follower is associated with increased follower job performance and organisational citizenship behaviour and negatively related to undesirable outcomes such as followers' intention to quit (see Colquitt et al., 2007; Dirks \& Ferrin, 2002). Trust, as a willingness to be vulnerable and accept risk in relationships (Mayer et al., 1995), is therefore a valued asset which leaders seek to foster and develop with their employees. An increasing body of evidence suggests that trust-related characteristics are seen as being universally important for leadership effectiveness (Den Hartog, 2018). The question then is, how can leaders' best harness that 'willingness' and what style of leadership is most suited for facilitating trust?

Around two decades ago, Dirks and Ferrin (2002) first meta-analysed the primary relationships of trust in leaders with antecedents, correlates and outcomes. However, due to the relative immaturity of the literature at the time they did not capture, beyond transformational and transactional leadership, how different leadership styles relate to trust. In recent years, several new leadership constructs have emerged in the literature. Given the frequency with which trust is proffered as an explanatory mechanism for the impact of these styles (e.g., Chen et al., 2014; Den Hartog, 2015; Miao et al., 2014), our meta-analysis offers 
an update of what is known and what remains to be studied in understanding this important relationship.

We synthesise the literature by providing meta-analytical correlations investigating the relative predictive validity of newer leadership variables over the more established full-range model (specifically the different transformational and transactional leadership components; Avolio \& Bass, 1991) in promoting trust and its associated performance outcomes. The core focus of our meta-analytical investigations is on the construct of trust in relation to the leader and a key aim is to identify which leadership style(s) are most critical for driving trust in the leader and which might be redundant. In doing so, we answer the call for leadership research to pay more attention to the comparative influence of different leadership models (e.g., Piccolo et al., 2012). Indeed, "pruning efforts, such as pitting competing theories against one another can help to build a more parsimonious understanding of the contexts in which theories are generalizable" (Banks et al., 2018; pg. 246). Thus, we aim to examine which leadership styles(s) are most critical for facilitating (or hampering) trust and we explore indirect effects of the different leadership styles on performance outcomes via trust in the leader.

Our paper goes beyond previous work (e.g., Dirks \& Ferrin, 2002; Hoch et al., 2018) and offers three significant contributions to the literature on trust, leadership, and Social Exchange Theory (SET). First, we explore the relative effects of a broad range of established and newer forms of leadership on our core variable of trust. Specifically, we examine how authentic, empowering, servant, paternalistic, ethical and abusive leadership relate to trust and whether these 'newer' leadership constructs explain variance in trust in the leader beyond the longer established styles included in the full-range model. In doing so, our research contributes to ongoing discussions within the leadership literature regarding construct 
redundancy (Banks et al., 2018) and serves to guide both future research efforts and leadership development practice.

Second, we assess whether trust in the leader as an underlying mechanism for the impact of leadership is distinct from a broader assessment of the relationship between the leader and follower. The quality of the relationship between a leader and follower is frequently suggested to form an important mechanism through which leaders affect outcomes (e.g., Wang et al., 2005). We focus on Leader-Member Exchange (LMX), which represents the quality of relationship between leaders and followers and can range on a continuum from high to low quality (e.g., Graen \& Uhl-Bien, 1995). Given that trust and LMX quality are both grounded in principles of SET, addressing the possibility for overlap and redundancy is warranted. Indeed, Liden and Maslyn (1998) questioned whether these two relational constructs essentially capture the same thing. We offer an empirical test of this issue. Further, in their review, Hughes et al. (2018) identified trust in the leader and LMX quality as the two most prominent social-relational mediating mechanisms for a host of different leadership styles. By positioning trust and LMX quality as parallel mediators in our analysis, we contribute to both the trust and LMX literatures and investigate the unique and differential role played by each in the relationship between leadership and follower performance outcomes.

Finally, we extend previous meta-analyses (e.g., Colquitt et al., 2007; Dirks \& Ferrin, 2002) by operationalizing trust as a multidimensional construct. Specifically, our analysis differentiates between cognitive and affective trust and examines the extent to which these are empirically distinct. We seek to determine if different leadership styles are more likely to encourage the development of one of these forms of trust over the other as well as how each base of trust relates to performance outcomes. This contributes to the ongoing debate about the dimensionality of trust and how trust is best operationalised (e.g., Dietz \& Den Hartog, 
2006; McEvily \& Tortoriello, 2011; Rousseau et al., 1998). In our assessment of these three competing mediators (cognitive trust, affective trust, LMX), we chose to focus only on studies that operationalise performance as an other-rated outcome with the aim of minimising common method biases in our model.

\section{Literature Review}

\section{Trust and Leadership}

Trust plays a critical role in most work relationship theories (Ferris et al., 2009; Fulmer \& Gelfand, 2012). Yet, the conceptualisation of trust forms a topic of considerable debate. Some scholars accept unidimensional definitions, describing trust as a psychological state consisting of a willingness to be vulnerable due to positive expectations of another party (e.g., Rousseau et al., 1998). However, multidimensional operationalisations distinguishing between different trust bases are also widely adopted. The most popular describes cognitive and affective forms of trust (McAllister, 1995). Cognitive trust refers to rational assessments of qualities such as ability and reliability that are built on the outcomes of previous interactions and judgements about similarity and the professional qualifications of the other party. In contrast, affective trust refers to the emotional ties in an interpersonal relationship and is informed by perceptions of the other party's motives, the extent to which they provide help and support, and frequency of interaction. Another widely used model focuses on ability, benevolence, and integrity as dimensions of trustworthiness (Mayer et al., 1995). Trust scholars have drawn parallels between these dimensions and affective and cognitive forms of trust. Specifically, ability and integrity have theoretical similarities with cognitive trust, while benevolence perceptions are more closely aligned with affective trust (Colquitt et al., 2012; de Jong et al., 2016; van der Werff \& Buckley, 2017). 
One context in which trust has received considerable attention is that of the leaderfollower relationship, where typically the role of trust is highlighted in the context of SET (Blau, 1964). Essentially, exchanges occur as leaders' express behaviours towards employees, which result in a felt obligation to reciprocate. According to SET, actions tend to be repaid in kind and this is likely to continue through a series of reciprocal exchanges (Cropanzano et al., 2017). For example, a leader may empower an employee, granting autonomy and discretion, and the employee may reciprocate through extra effort. These interactions extend beyond simple economic transactions and create diffuse obligations which can at times be unbalanced; this is when trust is particularly vital. Trust plays a key role in the development and deepening of positive social exchanges as it encourages obligation and reduces uncertainty around reciprocation (Konovsky \& Pugh, 1994). Trust therefore facilitates SET and can be used to operationalise leader-follower relationships (Colquitt et al., 2012). The facilitation of social exchanges through trust has become a prominent explanation in understanding the link between many leadership styles and their outcomes.

Over the past three decades, the form of leadership most associated with trust is transformational leadership, drawn from the full-range model (Jung \& Avolio, 2000). Transformational leaders motivate their followers to perform beyond expectations and to transcend self-interest in pursuit of group/organisational goals (Bass, 1985). The power of transformational leadership in furthering trust relates to the capacity for these leaders to inspire pride, admiration and respect and their ability to use social cues to evoke a sense of being appreciated and valued in followers ( $\mathrm{Ng}, 2017)$. Transformational behaviours are argued to result in followers trusting leaders and being willing to reciprocate by going over and above in their efforts. Transformational leadership consists of four dimensions; idealised influence, inspirational motivation, intellectual stimulation and individualised consideration. All four have been theoretically linked to trust (see Table 1). For example, core aspects of 
transformational leadership include inspiring followers to believe in a vision and challenging the status quo (Pillai et al., 1999). Trust is a well-established antecedent of risk taking in relationships (Mayer et al., 1995) and when followers trust their leader they are much more willing to accept such risk and show the effort needed to make the vision a reality. Transformational leaders are persuasive role models who signal integrity (a defining feature of cognitive trust) via their willingness to make personal sacrifices and their word-deed consistency (Avolio \& Bass, 1991; Kirkpatrick \& Locke, 1996). Also, individualised consideration can signal to employees that leaders are benevolent (a defining feature of affective trust) and will look out for their best interest, facilitating trust. All transformational subdimensions predict trust (e.g., Kelloway et al., 2012).

The full range model also distinguishes laissez-faire, which represents an absence of leadership, and transactional leadership styles (Bass, 1985). A transactional leadership style is based on economic exchange (Pillai et al., 1999) and leader influence over follower behaviour is achieved through contingent reward, where followers are rewarded for meeting agreed-upon-objectives, or management-by-exception (MBE), where the leader only takes corrective action, either active or passive, when things go wrong. Consistently engaging in contingent reward is likely to signal competence, reliability and predictability all of which denote aspects of ability or integrity (Mayer et al., 1995) or cognitive trust (McAllister, 1995). Thus, contingent reward helps followers trust that leaders will keep their word and deliver on promises (Jung \& Avolio, 2000). However, leaders who are disengaged (i.e., laissez-faire leadership) or engage in punitive behaviours (i.e., management-by-exception) likely undermine the development of trust (e.g., Kelloway et al., 2012).

Inherent in both the transformational dimensions and the contingent reward component are features of leadership that have been repeatedly associated with trust and subsequent performance (Ng, 2017; Podsakoff et al., 1990; Rubin et al., 2010). Research on 
emerging leadership styles have also found support for a strong link with trust in leadership (see Table 1). When compared to the full-range model, it may be the case that some of these more recent additions to the leadership literature may be stronger determinants of trust. More contemporary styles, such as ethical and servant leadership, emerged as a direct attempt to address a lack of trust and faith in organisational leaders (Avolio \& Walumbwa, 2014). As such, the moral tone of these styles may be more suited to facilitating trust compared to transformational leadership, which does not explicitly address ethics as a core tenet (Brown et al., 2005). There is some support for this contention (e.g., Hoch et al., 2018). For example, some of the core qualities associated with these more morally toned styles, such as transparency and openness (Korsgaard et al., 2002; Norman et al., 2010), play a central role in facilitating integrity (Mayer et al., 1995) or cognitive forms of trust.

Theories of leadership such as authentic, servant and ethical leadership (Dinh et al., 2014) can be grouped together in a 'moral approaches' category (Lemoine et al., 2019). Within this category, scholars typically draw on common theoretical arguments including SET to explain how these styles facilitate trust. For example, integrity is a core feature of authentic leadership and this, along with the unbiased processing of self-relevant information and fair treatment of followers, is likely to influence a follower's willingness to be vulnerable to their leaders and trust them (Ilies et al., 2005). Ethical leader behaviours are argued to influence follower's willingness to be vulnerable because of the psychologically safe working environment they create (Den Hartog, 2018). Ethical leaders for example, encourage employees to voice concerns and show fair treatment and balanced decision making (Brown et al., 2005) and empirical links to trust are found (e.g., Newman et al., 2014). SET has also been used to provide an explanation of how servant leadership influences the trust between followers and their leader (Lee et al., 2020). Servant leaders build trust by putting their own self-interests second to the interests of their followers and focusing on the greater good. In 
difficult or uncertain situations, followers should feel that they can rely on servant leaders to prioritize their welfare over organisational objectives, thus signalling affective trust and benevolent intent (e.g., Dirks \& Ferrin, 2002). Empirically, links between these moral approaches and trust have been found as summarised in recent meta-analytical work (Banks et al., 2016; Bedi et al., 2016; Hoch et al., 2018).

Other contemporary styles may also be important. For example, empowering leadership has been found to elicit trust (Huang et al., 2010). Empowering leadership is defined as promoting followers' self-directed and autonomous decision making, the giving and sharing of information, delegating authority and inviting input from followers (e.g., Kirkman \& Rosen, 1999). Leaders who empower subordinates, providing them discretion and latitude over decision making, make themselves vulnerable and demonstrate confidence; key features of trust (Zhang \& Zhou, 2014). Essentially, such empowering behaviours demonstrate to followers that the leader trusts them and followers are likely to reciprocate by trusting their leaders in return (Ferrin et al., 2008; Halbesleben \& Wheeler, 2015; Seppälä et al., 2011).

Paternalistic leadership is a style that comprises of authority and discipline as well as care and concern for followers and is conceptualised as three dimensions: authoritarianism, morality, and benevolence (Farh \& Cheng, 2000). Trust in the leader has been found to mediate the relationship between the morality and benevolence dimensions of paternalistic leadership and follower behaviour (Chen et al., 2014; Wu et al., 2012). The moral and benevolent dimensions are typically theorised to encourage follower reciprocation of positive leader behaviour leading to the development of trust over time (e.g., Chen et al., 2014). Specifically, positive and trustworthy leader behaviour encourages a shift from economic to social-exchange (Blau, 1964) suggesting that trust in the leader may explain the positive effects of leader morality and benevolence on followers' behaviour. Authoritarian leadership, 
however, is argued to create low levels of trust in leaders (e.g., Chen et al., 2014). Indeed, it is likely to operate in the opposite way to follower empowerment as the assertion of authority and control over followers may send the signal that leaders do not trust followers and encourage followers to accept and comply with the leaders' ideas without voicing dissent.

In addition, research has begun to explore the impact of destructive forms of leadership and their effect on outcomes via trust. Destructive leadership styles refer to voluntary acts committed by a leader which most people would perceive as harmful and deviant. The most studied of these is abusive supervision, defined as the extent to which supervisors engage in ongoing displays of verbal and non-verbal hostility (Tepper, 2000). Examples of abusive supervision include humiliating employees in pubic, mocking, belittlement, rudeness, breaking promises and other inappropriate behaviours (Tepper, 2000). In accordance with SET, trust should decrease over time as a result of these unfavourable exchanges with a leader which may even contribute to feelings of distrust of the leader (Tepper, 2007).

\section{$\underline{\text { Insert Table } 1 \text { about Here }}$}

As discussed, numerous leadership variables are theoretically and empirically associated with trust in the leader, which is often used as a mediator to explain the effects of leadership variables on follower outcomes. While other lenses are also used, the link between leadership, trust and outcomes is often built on the theoretical premise of SET. The proliferation of new leadership variables has led to concerns of construct redundancy particularly between the 'newer' conceptualisations of leadership and transformational leadership (Banks et al., 2018). The magnitude of correlation often observed between leadership styles (e.g., $r=.72$; Banks et al., 2018) is an issue for understanding the link between leadership and trust. While different leadership styles may relate to trust, we do not 
yet know whether effects are distinct from those of other leadership styles. Typically, leadership styles are studied in isolation, or at best alongside few others. As such, scholars in the leadership domain often fail to show the incremental effects of one leadership approach over others (Hunter et al., 2007; Piccolo et al., 2012). This makes it hard to discern the distinctiveness of leadership constructs (DeRue et al., 2011) and understand their relative ability to affect trust.

What is needed to resolve the fragmentation in the field are critical tests of theory where key leadership styles are examined concurrently to build a more parsimonious understanding of their value. Initial attempts have been made through meta-analytical methods (e.g., Banks et al., 2016; Hoch et al., 2018; Lee et al., 2018, Lee et al., 2020, Ng \& Feldman, 2015). In the present study, we seek to contribute to this literature by metaanalytically comparing the relative effects of eight leadership styles on trust and subsequent performance outcomes (see below). In the first stage, we compare the relative variance explained by each style over that explained by the full-range model of transformational and transactional leadership. Given the dominance of this model in the literature, and its broad coverage of leadership behaviours, it serves an important comparative function. Further, recent critiques of transformational leadership's theoretical foundations and practical relevance (e.g., van Knippenberg \& Sitkin, 2013), make it even more important to isolate whether other styles are meaningfully different.

In the second stage, we compare the relative importance of the contemporary leadership styles. Ideally, we would assess the relative importance of all six leadership styles (ethical, servant, empowering, paternalistic, authentic and abusive) together. However, the limited availability of primary data means that here we can only compare the effects of ethical, authentic, servant and abusive leadership on trust. 
The relatively fragmented and inconclusive nature of the current literature means it is not possible to make predictions as to which, if any, of the contemporary styles is the most important for building trust in the leader. Thus, we take an explorative approach to address this question. There are two related reasons for this. Firstly, as stated, each of the styles included here potentially relates to trust. Take for example two seemingly distinct leadership styles; empowering and ethical leadership. On the one hand, the delegation of responsibility and provision of autonomy bestowed by an empowering leader may facilitate reciprocal trust. At the same time, the role modelling and fairness inherent in ethical leadership should also facilitate trust. There is no clarity yet as to which of these two ostensibly distinct styles offers the strongest relationship with trust. In fact, compelling theoretical arguments, and empirical evidence, exist for each of the styles included in our analysis. As leadership styles are typically discussed in isolation, an a priori prediction of which style is the strongest predictor of trust is problematic.

A second issue is that broader leadership styles often combine a set of different dimensions e.g. the four dimensions of transformational leadership or the three dimensions of paternalistic. While the conceptual core of the different styles may be different, in practice these leadership constructs show overlap, particularly at the dimensional level. For example, the empowering dimension of servant leadership (Liden et al., 2015) clearly overlaps with empowering leadership. Such overlaps, common across many leadership styles, contribute to the problem of making a priori predictions of which style would be most prominent for engendering trust. As such, we propose the following two research questions:

Research question 1: What is the relative importance of the contemporary leadership styles over transformational and transactional leadership in predicting trust in the leader? 
Research question 2: Which contemporary leadership style is the most important for predicting trust in the leader - ethical, authentic, servant or abusive?

\section{Mediating Mechanisms: The Role of Trust in the Leader and LMX Quality}

Most meta-analyses examining trust test for direct relationships rather than positioning trust as a mediator of the leadership-performance link (for exceptions see Lee et al., 2018; Lee et al., 2020; Martin et al., 2016; Ng \& Feldman, 2015; Nohe, \& Hertel, 2017). Of these exceptions, only Lee et al. $(2018 ; 2020)$ and Nohe and Hertel, (2017) accounted for alternative mediation pathways measured concurrently. Trust in the leader is believed to be one of the key reasons why certain leadership behaviours are associated with positive employee outcomes. Empirically, trust in the leader has been found to mediate the relationship between numerous leadership styles and employee behavioural outcomes such as performance and OCB (e.g., Chen et al., 2014; Newman et al., 2014; Zhu et al., 2013). Trust facilitates these relationships due to its pivotal role in the formation and maintenance of social exchanges (Den Hartog, 2018; Dirks \& Ferrin, 2002; Konovsky \& Pugh, 1994) and ability to stabilize interpersonal relationships. When employees trust their leaders, they are more willing and able to focus cognitive resources on in-role and extra-role performance (Mayer \& Gavin, 2005).

In contrast, when a leader does not inspire trust, a follower's performance may suffer as they allocate resources toward 'covering their backs' (Dirks \& Ferrin, 2002). Here, we aim to test whether meta-analytic support exists for the role of trust as a key mediator in the relationship between the different leadership styles and performance outcomes. We focus specifically on task performance and OCB, as these are considered some of the most important outcomes in the organisational behaviour context (Banks et al., 2017). 
In considering alternative mediating mechanisms, we continue our focus on the attributes of the leader-follower relationship in line with their critical positioning in understanding the impact of leadership styles via SET. While trust in the leader is one important example of this, other, potentially overlapping or broader social exchange based variables, may also be in operation (Hughes et al., 2018). Most critical would be LMX quality which has been identified as the second most common operationalisation of SET with higher content validity than the more commonly used perceived organisational support (Colquitt et al., 2014). Given the leader-follower context of the relationships we are focused on, LMX quality is also the most contextually specific operationalisation of the SET relationship and its utility as a mediator in the relationship between leadership and outcomes has received considerable support (e.g. Gu et al., 2013). As such, trust and LMX quality offer the most theoretically coherent mediators for the SE relationship between leadership and performance related outcomes.

LMX, which is a relational approach to leadership, has been viewed as both a leadership variable in its own right and as a mediator explaining the effects of other leadership styles (e.g. Wang et al., 2005). This has resulted in confusion regarding the treatment of LMX in combination with other leadership styles. Inconsistencies in the literature about the conceptualisation and positioning of LMX have been carried over into meta-analytic work in the area. For instance, while Ng and Feldman (2015) describe LMX as a leadership style, others have positioned LMX, alongside trust in the leader, as an attitudinal outcome of leadership (e.g. authentic leadership, Banks et al., 2016; ethical leadership, Bedi et al., 2016). In addition, Dulebohn et al. (2012) treat LMX as a mediator, driven by styles such as transformational leadership. Hoch et al. (2018) argue that, unlike other leadership styles, LMX does not focus on leader behaviour and is thus more accurately captured as a 
relational perception, along with trust. Similarly, Dirks and Ferrin (2002) consider LMX a correlate of trust rather than an antecedent.

A related issue is the conceptual and theoretical similarities between LMX and trust and the fact that some scholars have positioned trust as a defining feature of LMX (Liden \& Graen, 1980). Indeed, the literature is often vague about the conceptual differences between trust and LMX. While we recognise that the two concepts are conceptually related, we see three key differences that influence how these variables might operate as SET mechanisms in the leader follower relationship. First, LMX focuses on followers' perceptions of the degree to which they have a positive relationship with their leader (Graen \& Uhl-Bien, 1995). In contrast, trust is a psychological state that represents a volitional choice to be vulnerable to another party (van der Werff et al., 2019). Second, trust as a willingness to be vulnerable, is based on expectations of the other party's behaviour. However, trust theorists argue that these expectations are informed by more than perceptions of the leader's past behaviour and that heuristic processes play a key role in trust formation (Baer et al., 2018; Kramer \& Lewicki, 2010). In contrast, LMX is argued to be built specifically on the history of exchanges between a leader and follower (e.g., Graen \& Uhl-Bien, 1995). Third, as observed by Brower et al. (2000), the foundations of LMX assume a level of reciprocity in the relationship that is not necessarily a feature of trust relationships (Korsgaard et al., 2015).

Based on their meta-analytic review, Dirks and Ferrin (2002) advocated that trust should be treated as a construct separate from LMX. In support, Scandura and Pellegrini (2008) found significant discriminant validity between trust and LMX. Despite this, theoretical explanations of their relationship with leadership both hinge on SET and comparisons between them are warranted to confirm that trust and LMX form distinct mediators of the leadership-performance relationship. As such, we propose: 
Hypothesis 1: Trust in the leader and LMX quality provide unique mediating roles in the relationship between leadership styles and performance related outcomes.

\section{The Differential Role of Cognitive and Affective Trust}

As noted, trust can be categorised according to whether it is more cognitively or affectively oriented. Implicit in this multidimensional view of trust is the assumption that affective and cognitive forms of trust ought to be to functionally different in terms of their nomological network. In the case of trust in leaders, it follows that affective and cognitive trust in the leader might have partially different antecedents and outcomes. For example, certain leadership styles may be more conducive to building affective trust than others. However, the empirical evidence for the affective-cognitive distinction is by no means indisputable. Dirks and Ferrin's (2002) meta-analysis found that cognitive trust had a stronger association with antecedents like procedural justice and attitudinal outcomes such as intention to quit compared to overall trust and showed a weaker relationship than overall trust with performance. Unfortunately, their meta-analysis had an insufficient number of studies to conduct analyses exploring the antecedents and outcomes of cognitive versus affective trust.

Theoretical and some initial empirical support exists for the idea that different leadership styles will influence the different trust bases. Affective trust is described as signifying a genuine care and concern for the relationship partner built on positive, enduring bonds (McAllister, 1995). Chen and colleagues (2014), for example, argue that the emphasis on benevolence and managing relationships inherent in paternalistic leadership makes it more likely to facilitate affective trust. Other styles which also prioritise the relationship and/or the needs of the follower are likely to be more conducive to building affective trust. For instance, a focus on caring action towards the follower and prioritising their interests is inherent in the definition of servant leadership (Lemoine et al., 2019). The same could be said about the 
individualised consideration aspect of transformational leadership, although many studies choose to collapse this into an aggregated measure of overall transformational leadership (e.g., Phong et al., 2018). Similarly, empowering leadership is a signal of significant investment in the relationship and the development of the follower, potentially at the expense of the leader. In contrast, McAllister's (1995) description of cognitive trust as being grounded in perceptions of reliability, competence and dependability makes it likely to be influenced by leadership styles that are focused on signalling the characteristics of the leader as competent and full of integrity. For this reason, it may be the case that styles such as authentic, ethical, transactional and transformational leadership will be influential in driving rational, cognitive judgements about a willingness to be vulnerable to the leader.

As noted, making specific predictions about the styles in relation to the bases of trust is hard due to the overlap between them on the dimensional level and the lack of studies focusing on these separate dimensions in relation to trust. Indeed, failure to explore differential effects for dimensions of a given style constitutes a considerable critique of the leadership literature overall (Banks et al., 2016; Hughes et al., 2018; Lee et al., 2020; van Knippenberg \& Sitkin, 2013). Most leadership studies aggregate measures of leadership to form an overall score (i.e., of overall servant leadership). However, if the conceptual core of the different styles is sufficiently different despite the dimensional overlap, this may still shine through in differential relationships with the two forms of trust. Our meta-analysis serves to provide initial evidence to identify which leaderships styles are associated more strongly with different bases of trust, thus providing support for their differing nomological networks. In line with this, we hypothesise:

Hypothesis 2: Different leadership styles will have differential relationships with cognitive and affective trust. 
The most studied leadership style in relation to the different bases of trust is transformational leadership, with similar effects for both trust bases being found (Chiang \& Lin, 2016; Conchie et al., 2012; Zhu \& Akhtar, 2014a; Zhu \& Akhtar, 2014b). However differential relationships with outcomes have also been demonstrated (e.g. Zhu et al., 2013). For example, Schaubroeck et al. (2011) reported a relationship between transformational leadership and cognitive but not affective trust. Conversely, they found a significant relationship between servant leadership and affective but not cognitive trust. Empirical studies investigating the relationship between the different bases of trust and performance also show mixed results with some studies reporting that affective trust is a more powerful antecedent (e.g., Miao et al., 2014; Yang \& Mossholder, 2010), while others report cognitive trust has a stronger relationship with performance (e.g., Zhu \& Akhtar, 2014a; Yang et al., 2009). Taken together, the literature on the differential impact of trust bases is by no means consistent and at the team level, a meta-analysis suggested the two bases demonstrate similar relationships with performance related outcomes (de Jong et al., 2016). Given this inconsistency, a key aim of our meta-analysis to explore the empirical evidence for affective and cognitive trust having different functional relationships with leadership styles and performance related outcomes. We hypothesise:

Hypothesis 3: Cognitive and affective trust will provide unique mediating roles in the relationship between leadership styles and performance related outcomes.

\section{Method}

To locate studies for inclusion in the meta- analysis, we first performed a comprehensive search for studies that examined trust in the leader published in or before June 2019. Our search was not constrained in terms of starting year. The first paper to meet our inclusion criteria was from 1988. We used several databases, including EBSCOHost, 
ProQuest, PsycINFO, and ScienceDirect. We used "trust*" and "leader*" as the initial search terms to identify manuscripts that included these terms in their title or abstract. This initial search returned around 40,000 results (depending on the database used) and included peerreviewed manuscripts as well as unpublished work such as dissertations and conference papers. The inclusion criteria required papers to: (i) report individual level, empirical, quantitative data; and (ii) provide a zero-order correlation between any measure of leadership styles and trust in the leader; or (iii) provide a zero-order correlation between trust in the leader and any other-rated (or objective) measure of follower performance or OCB. In order to calculate the sampling error, the study had to report sample size. In instances where the appropriate statistics were not provided in the original manuscript, efforts were made to contact corresponding authors and obtain the information necessary for inclusion. Overall, we identified a total of 170 empirical articles that met our inclusion criteria. 15 of these articles included multiple studies, yielding a total of 185 independent samples. Of these articles, 19 were unpublished (for full details of the papers included see Appendix B; all appendices mentioned in this article can be found online as supplemental materials).

In order to obtain correlations between leadership styles and performance outcomes, we first looked for previous meta-analyses that had included corrected correlations between leadership styles and other-rated performance and OCB (e.g., Banks et al., 2016). As can be seen in Appendix A, we relied on previous meta-analyses to provide most of the correlations between leadership styles and employees' performance and OCB (both other rated). For some relationships, we additionally searched for papers that had correlations between leadership styles (if not already available from other meta-analyses; see Appendix A). Details of the studies included in our analysis can be found in Appendix B which includes a breakdown of the articles used to produce meta-analytic correlations for each relationship. The coding of the studies was completed by one of the authors. Once completed, another author (who did 
not code the original studies) double coded $10 \%$ of the studies. The intercoder percentage of agreement across the study variables was $100 \%$ indicating no discrepancies in the coding of key information such as scale reliabilities and correlations between variables. Measures of trust in the leader were coded as affective, cognitive or overall trust in line with the coding protocol set out by de Jong and colleagues (2016). Measures that captured aspects of trust such as competence, reliability, integrity, consistency and fairness were coded as cognitive trust. The affective trust code was applied to measures that referenced benevolence, disclosure of information, concern for welfare or goodwill. Papers where the authors had addressed more than one of these dimensions in the same measure, or where the operationalisation of trust was more general, were coded as overall trust.

Our meta-analysis adopted the Hunter and Schmidt (2015) approach. This method produces a sample weighted mean correlation (r) as well as a mean correlation corrected for unreliability in both criterion and predictor variables, referred to as the corrected population correlation ( $\rho$ ). 90\% confidence intervals (90\% CI) of the sample-weighted mean correlation and the $80 \%$ credibility intervals $(80 \% \mathrm{CV})$ of the corrected population correlation were also calculated and reported. Furthermore, in order to better determine whether moderators were present, we calculated the percentage of variance accounted for in the corrected population correlation by sampling and measurement error (\% VE).

In order to examine the mediating effects, relative and incremental predictive validity issues addressed in our research questions, we used meta-analytical path analyses (see Viswesvaran \& Ones, 1995). Relative weights analysis assesses the relative contribution (i.e., relative importance) among several (often correlated) independent variables in a regression analysis. Relative weights analysis converts the total variance predicted in a regression model (i.e., R squared) into weights that indicate the proportional contribution of the various independent variables. Specifically, these weights can be interpreted as the percentage of 
variance explained in the outcome (e.g., trust in leader) that can be attributed to each independent variable (i.e., leadership style). Relative weights analysis deals with the problem caused by correlated predictors by using a variable transformation approach that takes into account a variable's contribution to an outcome by itself and in combination with other predictor variables (see Johnson, 2000; Johnson \& LeBreton, 2004; LeBreton \& Tonidandel, 2008; Tonidandel \& LeBreton, 2011, for a detailed discussion of relative weight analysis). Relative weights analysis is commonplace within meta-analyses in the management field (see Hoch et al., 2018; Kurtessis et al., 2017; Lee et al., 2018; Lee et al., 2020). To conduct relative weights analysis, we first produced a correlation matrix, which included metaanalytic correlations between all study variables (where possible). Using this correlation matrix, we conducted relative weights analyses, using Tonidandel and LeBreton's (2011) guidelines.

All path models were estimated using robust maximum likelihood estimation within MPlus (version 7). In order to do this, we first calculated the harmonic mean of each subsample size in order to arrive at a sample size for our analysis. This was required due to the fact that sample sizes varied across the various cells of the aforementioned correlation matrices (Viswesvaran \& Ones, 1995).

\section{Results}

\section{Relative Effects of Leadership on Trust}

The first aim of this meta-analysis was to determine the extent to which various contemporary leadership styles predicted trust in the leader above the effects of transformational leadership and transactional leadership (i.e., Research Question 1). Rather than focus on overall transactional leadership, based on our findings, we decided to focus on contingent reward as our measure of transactional leadership given this dimension had much 
stronger effects than MBE (see Table 3). To examine the relative effects of the contemporary leadership styles over the full-range model, we first calculated the main effects of each leadership style, including transformational leadership and contingent reward, on trust in the leader. We also calculated correlations between the newer leadership styles and transformational and contingent reward leadership (see Appendix A). As can be seen in Table 2, all leadership styles were significantly associated with trust in the leader.

Next, our relative weights analysis assessed the relative contribution of each leadership style to trust in the leader and results are shown in Table 4. The results suggest that the newer forms of leadership all have a relatively large association with trust in the leader. For instance, servant, authentic, ethical, empowering, and paternalistic leadership all had a relative weight over $35 \%$. In the case of paternalistic leadership, both the moral $(28.53 \%)$ and benevolent (38.27\%) dimensions explained greater variance than transformational leadership (16.59). We could not include transactional leadership in this analysis due to a lack of primary studies. In the case of abusive supervision, this leadership style had a lower relative weight $(21.83 \%)$ than did transformational leadership (39.01) or contingent reward (39.16).

\section{$\underline{\text { Insert Table 2, } 3 \text { and } 4 \text { about Here }}$}

The utility of the newer forms of leadership is further emphasised in the incremental predictive validity analysis, included in Table 5. This table reports variance explained in the criterion (trust in the leader) by transformational and contingent reward leadership and the incremental variance explained by each of the other forms of leadership (i.e., authentic, servant, ethical, empowering, paternalistic, and abusive). Results demonstrate that each of these six leadership styles explained significant variance in trust in the leader over transformational and contingent reward leadership. The amount of additional variance explained varied across the leadership styles. Abusive supervision explained the least additional variance (6\%). Ethical leadership and authentic leadership both explained $10 \%$ 
beyond transformational and contingent reward leadership, while empowering leadership explained an additional $11 \%$. The leadership styles which explained the most additional variance were servant (20\%) and paternalistic leadership (58\% across the three dimensions). However, it must be noted that for paternalistic leadership we were only able to assess incremental validity over transformational leadership as too few primary studies examined the association between paternalistic leadership and contingent reward. Taken together, the results of the analyses suggest that while all the leadership styles tested demonstrated incremental predictive validity, servant leadership style was best able to explain incremental validity over transformational and contingent reward leadership.

\section{$\underline{\text { Insert Table } 5 \text { about Here }}$}

Our second research question focused on exploring the relative importance of the newer leadership theories. Thus, besides exploring the relative contribution of the newer leadership styles with transformational and transactional leadership, we also conducted relative weights analysis comparing these newer styles with one another. Too few primary studies existed to examine all styles together in one analysis. Therefore, Table 4 shows the relative weights analysis comparing the associations between servant, ethical, authentic and abusive leadership to trust in the leader. For overall trust in the leader, servant leadership demonstrated the largest relative contribution (31.39\%) compared to the other styles.

\section{Mediating Mechanisms: The Role of Trust in the Leader and LMX Quality}

Table 6 highlights the meta-analytic correlations between trust in the leader and performance and OCB (other-rated). As can be seen in the table, trust in the leader was significantly correlated with both performance $(\mathrm{p}=.30)$ and OCB $(\mathrm{p}=.34)$. To address Hypothesis 1 regarding the mediation effects of trust in relation to LMX, we conducted path analysis (MASEM), which required additional meta-analytic correlations between the 
leadership styles and LMX as well as the outcome variables (see Appendix A). The mediation analysis, presented in Table 7, shows that all leadership styles had a significant indirect effect on performance through trust in the leader. For OCB, a significant indirect pathway via trust in the leader was found for all leadership styles with the exception of paternalistic leadership. LMX was also found to mediate the effects of all the leadership styles on performance except for the authoritarian dimension of paternalistic leadership.

\section{$\underline{\text { Insert Table } 6 \text { about Here }}$}

Comparing the size of the indirect effects suggests that compared to LMX, trust in the leader explained significantly more variance in the relationship between many leadership styles and job performance. Specifically, significantly larger indirect effects were found for transformational, servant, and ethical leadership and performance via trust compared to LMX. This is indicated by non-overlapping 95\% confidence intervals. Except for paternalistic leadership, we also found trust to be the strongest mediator for all leadership styles when OCB was the outcome of interest. Significantly larger indirect effects were found for transformational, servant, authentic, empowering, abusive, and ethical leadership and OCB via trust compared to LMX. The findings show LMX and trust in the leader are distinctive explanatory pathways which can each explain unique variance supporting Hypothesis 1.

\section{The Differential Role of Cognitive and Affective Trust}

The final aim of our meta-analysis was to explore the role of cognitive and affective trust as separate dimensions of trust in the leader. Enough primary studies were available to explore the effects of transformational, servant, authentic, ethical, abusive, and empowering leadership on cognitive and affective trust. The aforementioned leadership styles predict 
cognitive and affective trust to a similar extent and no significant differences were found in these main effects (see Table 2).

The relative effects of the leadership styles on cognitive and affective trust over transformational leadership are shown in Table 3. The relative weights analysis highlights differences across the two bases of trust, supporting Hypothesis 2. Specifically, transformational leadership is the dominant predictor of cognitive trust and thus explains a larger amount of variance compared to all other leadership styles. However, for affective trust, ethical leadership (63.17) and servant leadership (56.86) explained more variance compared to transformational leadership. As was the case for overall trust in the leader, we also conducted relative weights analysis comparing the associations between servant, ethical, authentic and abusive leadership to cognitive and affective trust in the leader. For cognitive trust in the leader, authentic leadership showed the largest contribution (34.92\%), whereas ethical leadership had the largest association with affective trust (34.38\%).

As shown in Table 4, the incremental predictive validity analysis highlights that servant, ethical, and authentic leadership showed modest incremental predictive validity over transformational leadership for cognitive trust. Each of these styles demonstrated an $11 \%$ increase in the variance explained above transformational leadership. Empowering leadership accounted for an additional 9\% variance in cognitive trust over transformational leadership, while abusive supervision showed no evidence of incremental validity. Both servant and ethical leadership predicted affective trust to a greater extent than transformational leadership, accounting for $31 \%$ and $30 \%$ additional variance respectively. Authentic leadership accounted for an additional $22 \%$ of the variance of affective trust.

In terms of predicting performance outcomes, both cognitive and affective trust have significant correlations with performance and OCB (see Table 6). Furthermore, as shown in 
Table 7, affective trust significantly predicted both performance and OCB when included in a regression with cognitive trust. In contrast, cognitive trust did not predict either outcome. This suggests that the effects of trust in the leader on performance outcomes are driven by the affective rather the cognitive component and provides further support for the differential effects of these bases of trust. Finally, we conducted MASEM analysis to further explore trust in the leader as a mediator between leadership and performance outcomes focusing on the differential effects of cognitive and affective trust (see Table 8). Again, we included LMX as an additional mediator.

Comparing the two bases of trust first, any positive indirect effects were driven purely by affective trust. Conversely, for each leadership style, cognitive trust demonstrated negative indirect effects. Affective trust and LMX accounted for unique variance in the mediation analysis. Which was the strongest mediator varied by leadership style and as a function of outcome. In the case of transformational leadership, affective trust was the stronger mediator for both OCB (.18) and performance (.10) when compared to LMX. A similar pattern of results was found for abusive supervision as the negative indirect effect for affective trust was consistently stronger for both performance (-10) and OCB (-.13). Overall, the analysis suggests differential effects do emerge as a function of the trust base (Hypothesis 3).

\section{Insert Table 7 and 8 about Here}

\section{Discussion}

The seminal works of scholars such as Mayer et al. (1995) and Dirks and Ferrin (2002) helped to cement trust as a vital concept within the organisational literature. Since then, interest in the topic of interpersonal trust at work has continued to grow. Nowhere has this been more evident than within the leadership domain where trust is frequently identified as a key variable in the leadership process (e.g., Chan \& Mak, 2014; Wu et al., 2012; Zhu et 
al., 2013). However, to date, trust and leadership research has produced a complex and cumbersome literature that undermines understanding and the development of clear practical guidance for leaders. The aim of this meta-analysis is to bring some much-needed clarity to the area in four key ways. First, we synthesise existing empirical work to produce robust estimates of the correlations between eight leadership styles and follower trust in the leader. Second, we explore the relative importance of these different leadership styles for facilitating trust. Third, we investigate the role of LMX quality and trust in the leader as competing SET mediators. Finally, we examine the differential role of cognitive and affective trust as SET mechanisms in the relationship of leadership styles and follower performance related outcomes. We discuss our findings in relation to our research questions and hypotheses below.

\section{Relative Effects of Leadership Styles on Trust in the Leader}

First and foremost, our findings support the belief that trust is a core mechanism through which the impact of leadership behaviours can be realised. Our results provide evidence that ethical, servant, authentic, abusive and empowering leadership all offer some incremental effects on trust in the leader compared to transformational and contingent reward leadership (see Table 5). Of these styles, servant leadership demonstrated the largest incremental effects suggesting it offers unique effects for trust that extend beyond those captured by the fullrange model. One of the elements of servant leadership that is likely to distinguish it from other styles is the emphasis placed not only on a leaders' moral responsibility to the success of the organisation, his or her subordinates, but also the organisation's customers, and the wider community (Lemoine et al., 2019). In other words, servant leadership's distinctive focus is on serving multiple stakeholders. Our findings suggest that this wider stakeholder focus may be important for building trust with followers. 
An interesting finding to emerge was that abusive supervision, a destructive leadership style, had the weakest association with trust in the leader compared to the other styles included in our analysis. Abusive supervision had the smallest overall correlation with trust in the leader and demonstrated no incremental effects above transformational and contingent reward leadership. In their recent review, Tepper et al. (2017) highlight that very few studies have compared the effects of abusive supervision within more comprehensive models of leadership behaviour. Indeed, the authors called for research exploring "...the relative importance of abusive supervision in predicting leadership criteria...compared to traditionally studied leader behaviours" (pg. 136). Our findings suggest that, compared to transformational and contingent reward leadership, abusive supervision has little impact on trust. However, it is important to highlight that our analysis treats these styles separately and does not account for the fact that leaders may engage in a wide variety of behaviours (e.g., demonstrate multiple leadership styles simultaneously). Studies have demonstrated that supervisors who act abusively may also behave supportively within otherwise high-quality relationships, a combination that can cause more damage than abusive behaviour alone (e.g., Duffy et al., 2002; Lian et al., 2012; Xu et al., 2015).

Reflecting further on the findings, paternalistic leadership also appears to be a style which is particularly effective over transformational leadership in eliciting followers' trust in the leader. Several parallels exist between paternalistic and transformational leadership. For instance, the idealised influence of transformational leadership is conceptually close to the morality dimension of paternalistic leadership, as it raises the consciousness of followers to higher levels of morality and motivation by appealing to their ideals and moral values (e.g., Bass, 1985). However, despite these overlaps, our analysis highlights a distinct relationship between paternalistic leadership and trust in the leader, thus lending support to the argument 
that these two leadership styles are empirically distinct (see Cheng et al., 2004; Hiller et al., 2019).

A critical distinction between paternalistic and transformational leadership is the extent to which leaders are involved with the welfare of their followers. Transformational leaders provide individualised care, but this is usually limited to the work context. Paternalistic leaders, on the other hand, are theorised to also provide such care in their followers' work and personal lives (Chen et al., 2014). Further, the benevolence dimension of paternalistic leadership was the strongest predictor compared to transformational leadership. This finding is consistent with the recent work of Hiller and colleagues (2019) which highlighted that the benevolence component is not being fully captured in other mainstream leadership styles. Our finding that benevolent leadership is particularly important for trust is in line with many theoretical works which place benevolence as a critical determinant of trust (e.g., Mayer et al., 1995). Benevolence denotes care and concern and behaviours that signal having the employee's best interests at heart are likely to evoke employee gratitude and indebtedness (Chen et al., 2014), thus helping to fuel social exchanges. As a relatively new addition to leadership discourse, it is of value to see how paternalistic leadership configures alongside other contemporary approaches. Also, given that paternalistic leadership has been studied more in non-Western contexts, it is of interest in future work to address whether these effects generalise to Western contexts.

Finally, it is interesting to note that all the leadership variables included in our analysis are significantly correlated with trust in the leader. This finding can be interpreted in several ways. One explanation is that all these leadership styles can influence follower trust. Some leaders may, for example, create trust through providing autonomy (i.e., empowering leadership), whereas others may do so by showing behavioural integrity (i.e., authentic leadership). Alternatively, it could be argued that there is a large empirical overlap between 
leadership styles, some of which may be redundant (Banks et al., 2018). As noted, some of this potential redundancy is particularly evident when looking at the underlying dimensions proposed to be part of the different leadership styles. Relatedly because the scales used to measure leadership styles are typically follower rated, responses may represent followers' overall evaluation of their leader rather than any specific leadership behaviour or style (e.g., Lee et al., 2015). This is an issue within the wider leadership literature that needs to be addressed in future research. Despite the overlap between the leadership styles alluded to above, our relative weights and incremental validity analysis can begin to highlight where uniqueness between them does in fact exist.

\section{Relative Effects across Contemporary Leadership Styles}

An ancillary aim of the current research was to estimate the relative effects of ethical, authentic, servant, and abusive leadership. As discussed, the leadership literature has been critiqued for construct redundancy, with high correlations being observed between supposedly distinct leadership styles (e.g., Banks et al., 2018). One way to address this issue is through critical tests of theory where popular leadership styles are examined concurrently to determine the value of each construct. Several recent meta-analyses have made progress in this regard (e.g., Banks et al., 2016; Hoch et al., 2018; Lee et al., 2018; Lee et al., 2020; Ng \& Feldman, 2015) and we seek to contribute to this literature.

Our findings have important implications for the leadership field. On the one hand, the high correlations observed between servant, ethical, and authentic leadership further highlight the theoretical and empirical overlap between these morally-based constructs. Lemoine and colleagues (2019) argued that the similar effects observed among these different moral approaches has led to "conceptual vagueness regarding their unique content" (pg. 177). On the other hand, we find evidence that each of these styles has relative importance for trust depending on how it is measured. Our results suggest authentic leaders are best able to build 
cognitive trust in followers, while ethical leaders are best able to develop affective trust. These findings help in mapping the differing nomological networks of cognitive and affective bases of trust in terms of differing relationships with antecedents. Going forward, our results also highlight a means for the leadership literature to address current critiques by refining theoretical and empirical investigations of leadership to establish a more accurate picture of distinct effects. Exploring differential effects for the dimensions of a given style would allow for less overlap and more specific, granular predictions in terms of outcomes. It is likely that, such efforts would reveal a more nuanced and complex picture due to the multi-faceted nature of leadership styles.

Take for example, servant leadership which is typically conceptualised as a multidimensional construct. The most common measure of servant leadership (Liden et al., 2008 scale) includes seven dimensions: emotional healing, creating value for the community, conceptual skills, empowering, helping subordinates, grow and succeed, putting subordinates first, behaving ethically. As servant leadership is multi-faceted, the link with the two bases of trust is likely to be through different dimensions. One could argue servant leaders create trust by acting with integrity and ethics (thus suggestive of an important link to cognitive trust). However, the care and concern implied by other aspects of the style (such as the empowerment component) may be germane for building affective trust. Such a discussion portrays the complexities of trying to tease out the differential nature of the relationship for a given leadership style with the bases of trust. In Appendix C (online), we offer a table that indicates the strength of the theoretical link between the dimensions of a given style with cognitive and affective trust as well as LMX quality. Any efforts to further test these links should go hand in hand with improved study design that can reduce endogeneity biases and provide more accurate estimates of the relationship between leadership variables and outcomes (e.g., Antonakis et al., 2010; Hughes et al., 2018). 


\section{Mediating Mechanisms: Trust in the Leader and LMX Quality}

Trust in the leader and LMX quality represent competing SET based variables that can explain the link between leadership styles and follower outcomes. While LMX is one of the most frequent operationalisations of SET, trust and particularly affective trust is among the most content valid (Colquitt et al., 2014). Overall, the results of our mediation analysis provided two key findings. Firstly, LMX quality and trust in the leader were distinct mediators each demonstrating significant indirect effects between leadership and both performance and OCB. The exception to this overall pattern relates to paternalistic leadership. Specifically, we found that trust did not mediate the relationship between any of the dimensions of paternalistic leadership and OCB, while LMX did not mediate the authoritarian dimension of paternalistic leadership. Taken together these findings highlight that LMX and trust in the leader provide distinctive exploratory pathways for both other-rated performance outcomes.

The second notable finding from our mediation analysis was that for most leadership styles, trust in the leader explained a greater proportion of the overall indirect effect with performance and OCB compared to LMX quality. The exceptions were the relationship between empowering leadership and performance and between the moral and benevolent dimensions of paternalistic leadership and OCB; where LMX explained a larger proportion of the indirect effect. These findings are interesting, especially as previous meta-analyses comparing the mediating role of LMX and trust have generally found stronger indirect effects between specific styles of leadership and follower outcomes via LMX compared to trust. In their meta-analysis, Nohe and Hertel (2017) found that LMX was the strongest mediator between transformational leadership and OCB. Similarly, Lee and colleagues (2020) found LMX was the primary mediating mechanism for relationships between servant leadership and a range of employee outcomes as well as between empowering leadership and job 
performance, although trust was more important for OCB. Our findings support Lee et al.'s (2018) finding of larger indirect effects between empowering leadership and OCB via trust compared to LMX and vice versa for employee performance. However, the overall pattern of our results highlight trust as the primary mediating mechanism in contrast to both Nohe and Hertel (2017) and Lee and colleagues (2020). These differences may be explained by differences in the empirical studies that inform our analyses. Lee and colleagues (2020) and Nohe and Hertel (2017) both draw on a smaller sample of primary studies, used a mixture of self-rated and non-self-rated employee outcomes, and included additional non SET mediators alongside trust and LMX.

In summary, our mediation findings suggest that both trust and LMX offer distinct pathways and provide support for the view of them as unique mediating mechanisms. The uniqueness observed in our analysis may be indicative of the differing extent to which these two mediators are in fact capturing the SET process. While LMX is a popular operationalisation of SET, it has been argued that LMX measures (e.g., LMX-7; Graen \& Uhl-Bien, 1995) suffer from a shortage of items which are explicitly 'exchange' based (Bernerth et al., 2007). For LMX, the SET conceptualisation may be more diffuse, often reflecting more role-making aspects of the relationship (Bernerth et al., 2007). Trust, and in particular affective trust, may offer a more accurate, focused operationalisation of SET. More generally, our mediation results underscore the value of testing multiple social-exchange mediators.

\section{The Differential Role of Cognitive and Affective Trust}

An increase in studies adopting multidimensional operationalisations allowed us to explore the effects of the cognitive and affective components of trust. Interestingly, when considered in parallel, affective trust in the leader was the only significant predictor of 
performance and OCB. This constitutes an important finding as debate continues about the extent to which these bases of trust are empirically distinct (van Knippenberg, 2018). From a SET perspective, our findings suggest that affective trust is particularly powerful for facilitating the exchange process between a leader and follower. Indeed, Colquitt and colleagues (2014) identified affective trust as one of the most 'content-valid indicators of social exchange relationships' (p. 609). Further, such a finding is consistent with the view that affective trust represents a more enduring and powerful form of trust (McAllister, 1995; Williams, 2001).

We note that a meta-analysis by de Jong et al. (2016) revealed that cognitive and affective team trust predicted team performance to a similar extent. Our findings paint a different picture for trust in the leader at the individual level. Specifically, we found evidence that affective trust in the leader is a more powerful predictor of OCB and performance compared to cognitive trust suggesting that, in the context of a relationship with one's leader, affective trust may be more critical. This may be symptomatic of differences in how the social exchange relationship operates in leader-follower exchange relationships compared to team relationships. The power differential and stronger hierarchical dependence inherent in the leader-follower relationship (Emerson, 1962; Lapidot et al., 2007) may result in a situation where issues such as care, concern and benevolence are more important for performance or citizenship. In contrast, in less hierarchical team level relationships, where team members may work more interdependently, aspects of cognitive trust such as the competence and dependability of one's team members may be of greater (or equal) concern.

We also find that servant and ethical leadership styles are more influential in driving affective trust than the dominant theories of the full-range model. Servant and ethical leaders put their followers first, even at the expense of themselves and organisational objectives (Brown et al., 2005; Lee et al., 2020). This represents a key point of conceptual departure as 
transformational leaders are more concerned with advancing organisational objectives (Bass, 2000). The findings reinforce the view that studies should adopt multidimensional measures to tease out which form of trust is more important in creating desirable consequences and which leadership styles are most likely to facilitate that trust. When studies choose to adopt overall measures of trust, these nuances may be missed.

Turning to our mediation analysis, affective trust and LMX quality jointly explained the indirect effects of leadership styles with outcomes whereas cognitive trust did not explain the relationship in the expected direction. Interestingly, affective trust explains a larger proportion of the indirect effects between all leadership styles and OCB. This is supportive of the argument that affective trust most accurately captures features of the social exchange relationship by evoking sentiments such as commitment and intrinsic significance (Colquitt et al., 2014). As discretionary behaviour, OCB represents important SET currency (Lee et al., 2019) that is especially useful in maintaining balanced exchanges (e.g., Ilies et al., 2007). Finally, the negative indirect effects found for cognitive trust are likely indicative of a suppression effect. According to Cohen and Cohen (1983), a suppression effect occurs whenever one of the three possible pair-wise correlations among these three variables is less than the product of the other two. The suppression effect likely comes from the multicollinearity between the bases of trust, LMX and the leadership variables. For instance, a high correlation $(\mathrm{p}=.77)$ was observed between cognitive and affective trust (see Table 6 ).

\section{Practical Implications}

A number of practical implications can be garnered from these findings. It is important to reflect on the fact that the relationship between affective trust in the leader and performance outcomes was significantly stronger than that of cognitive trust. Importantly, this finding differed to that of team trust which found equal effects for both bases of trust (de Jong et al., 2016). As such, our meta-analysis suggests that organisations looking to enhance 
leader-follower trust should look to facilitate this base of trust in particular. Employee affective trust is driven by a perception that the leader has good intentions towards them and cares for their wellbeing. Therefore, training aimed at equipping managers with the skills to develop such positive orientations in employees where affective trust can emerge would be highly beneficial. The most practical strategy for meaningfully targeting trust in this way is to focus on developing those leadership styles most associated with affective trust. Based on the findings of this meta-analysis, leadership development programs targeted at ethical and servant leadership would be particularly beneficial. Equally, organisations could look to select leaders who demonstrate an inclination towards a given leadership style. For example, many leadership assessment processes now include the measurement of leadership styles through practitioner-oriented scales such as the MLQ or integrity tests. Through adopting such suggestions, organisations will not only benefit from enhanced performance and OCB, but many of the other salutatory benefits which may follow from trust in the workplace. It is also important to note, however, that many leadership styles have significant direct effects on either performance or OCB over and above the indirect effects observed via trust or LMX. If organisations are purely interested in influencing performance or OCB, our analysis suggests that transformational and servant leadership have the largest overall effects on these variables respectively.

\section{Limitations \& Future Research Directions}

Our meta-analysis is impacted by the limitations of the studies which we have included. In particular, we note two key limitations in the trust and leadership literatures. First, a lack of consensus around the measurement of trust is well documented in the literature and leading scholars in the area have called for a more unified approach (e.g. Dietz \& Den Hartog, 2006; McEvily \& Tortoriello, 2011). As noted by a number of researchers (e.g., Aguinis et al., 2010; Hoch et al., 2018), every meta-analytic study is subject to a variety of subjective 
judgements; for example, when it comes to retrieving relevant studies and the coding of data. To reduce issues related to the former, we conducted an exhaustive search of studies on leadership and trust in the leader. Second, to address coding issues, a proportion of the data was double coded to minimize judgement impacts. Despite these efforts, these limitations may have unintentionally influenced the findings. On a related note, we recognise that some of the comparisons drawn in our analysis were based on relatively small numbers of studies and, in these instances, results should be interpreted with some caution.

Another limitation acquired from the empirical literature is that of causal inference. A large proportion of the studies on trust in leaders have been conducted cross-sectionally with only a handful of time-lagged designs (e.g., Newman et al., 2014; Zhang \& Zhou, 2014) or experimental (Hoyt \& Blascovich, 2003). This limits our ability to demonstrate causality in the relationship between leadership styles, trust and performance outcomes. In addition, McAllister (1995) argues that cognitive trust is a necessary precondition for the development of affective trust. Typically, however, trust is captured as a static variable rather than a dynamic construct which changes over time. Further research is therefore required to investigate these relationships using longitudinal and experimental methods to more accurately account for the issue of time. Despite this, a strength of our meta-analysis was that we only focused on other-rated outcomes for performance and OCB. This goes some way in helping alleviate concerns regarding common method variance (Podsakoff et al., 2003).

It is important to consider our meta-analytic findings in relation to the wider leadership literature. The literature has been subject to high profile critiques regarding the conceptualisation, measurement and study design (e.g., Antonakis et al., 2010; Hughes et al., 2018). Critiques of transformational (van Knippenberg \& Sitkin 2013), and authentic (Alvesson \& Einola, 2019) leadership highlight one issue of particular relevance to the current analysis. Both critiques point out that the conceptualisation and operationalisation of 
these prominent leadership styles confound the variable with its effects. For instance, in relation to trust, it is argued the perception that the leader instils trust is conceptualised as part of the charismatic (i.e., idealised influence) dimension of transformational leadership and thus part of the independent variable as well as the mediating variable. Worryingly, this tautology and a priori positive framing may also be relevant to the scale used to measure ethical leadership which asks followers directly whether their leader "can be trusted" (Brown et al., 2005). In fact, the value-based and moral behaviour models of leadership in general tend to correlate heavily with constructs traditionally examined as outcome variables (e.g., trust) and thus are carriers of endogeneity bias (Banks et al., 2018). Such an explanation may, at least, partly explain the high correlations found between the different leadership styles and trust in the leader. To begin to address these issues, we echo the call for future research to focus on the measurement of specific behaviours enacted by leaders rather than only broad, over-positive leadership styles (e.g., Van Quaquebeke \& Felps, 2018).

The focus of the primary studies involved in our sample led to some further limitations and highlight important areas to be addressed by future empirical work in the area. First, the nascent nature of some of the styles included in our meta-analysis, combined with the rarity of studying multiple styles within a single empirical study, means it is not yet possible to compare the influence of all styles within a single model. We recommend that scholars investigating novel leadership styles include the role of established styles in their models to determine issues of relative influence. In addition, an insufficient number of primary studies were available for some of the leadership styles to meaningfully test the mediated relationships for both cognitive and affective trust. As such, greater uptake of multidimensional measures of trust are needed to help to tease out their differential roles. As noted, many styles also have subdimensions that may logically be more related to cognitive or affective forms of trust. As research often only reports on the overall style, it is not 
currently possible to disentangle such effects. More studies focusing on the specific subdimensions can help remedy this and the table in Appendix C may serve as a useful guide. We also did not find sufficient studies which examined (or reported examining) trust in senior leadership, making comparisons across leader level impossible. The relative homogeneity of studies in the field in terms of leader level is a limitation as well as a potential area for future research.

Finally, it is important to acknowledge mechanisms other than LMX and trust are likely to be operating. For instance, future work could consider other related variables which revolve around the relationship between the leader and follower such as relational identification. Another interesting avenue may be to consider the relationship between the three dimensions of paternalistic leadership and OCB which were not found to be mediated by trust in leader. Instead the dimensions of paternalistic leadership had relatively large direct effects on followers' OCB which may indicate that paternalistic leadership is a leadership style with the potential to directly impact on follower behaviour. Alternatively, it may that more motivational mediators such as self-efficacy may better explain the indirect effect between paternalistic leadership and follower OCB (e.g., Lin et al., 2015).

To conclude, in the complex, interdependent contexts of contemporary organisations it is no longer appropriate to see trust as an exogenous factor, something of benefit if it should happen to be present. The findings of this meta-analysis attest to this, having demonstrated strong relationships between affective trust and performance outcomes. If trust is a defining component of leadership (e.g., Shamir \& Lapidot, 2003), determining which styles are most relevant for facilitating its expression is of fundamental importance to both the trust and leadership literatures. Our findings would suggest that ethical and servant leadership hold most promise in this regard. So too may paternalistic leadership, following further empirical study. 


\section{References}

Aguinis, H., Dalton, D. R., Bosco, F. A., Pierce, C. A., \& Dalton, C. M. (2010). Metaanalytic choices and judgment calls: Implications for theory building and testing, obtained effect sizes, and scholarly impact. Journal of Management, 37, 5-38.

Alvesson, M., \& Einola, K. (2019). Warning for excessive positivity: Authentic leadership and other traps in leadership studies. The Leadership Quarterly, 30, 383-395.

Antonakis, J., Bendahan, S., Jacquart, P., \& Lalive, R. (2010). On making causal claims: A review and recommendations. The Leadership Quarterly, 21, 1086-1120.

Avolio, B. J., \& Bass, B. M. (1991). The full range leadership development programs: basic and advanced manuals. Binghamton, NY: Bass, Avolio \& Associates.

Avolio, B. J., \& Walumbwa, F. O. (2014). Authentic Leadership Theory, Research and Practice: Steps Taken and Steps that Remain. In D. V. Day (Ed.), Oxford handbook of leadership and organizations. New York, NY: Oxford University Press.

Baer, M. D., Van Der Werff, L., Colquitt, J. A., Rodell, J. B., Zipay, K. P., \& Buckley, F. (2018). Trusting the "look and feel": Situational normality, situational aesthetics, and the perceived trustworthiness of organizations. Academy of Management Journal, 61, $1718-1740$. 
Banks, G. C., Engemann, K. N., Williams, C. E., Gooty, J., McCauley, K. D., \& Medaugh, M. R. (2017). A meta-analytic review and future research agenda of charismatic leadership. The Leadership Quarterly, 28, 508-529.

Banks, G. C., Gooty, J., Ross, R. L., Williams, C. E., \& Harrington, N. T. (2018). Construct redundancy in leader behaviors: A review and agenda for the future. The Leadership Quarterly, 29, 236-251.

Banks, G. C., McCauley, K. D., Gardner, W. L., \& Guler, C. E. (2016). A meta-analytic review of authentic and transformational leadership: A test for redundancy. The Leadership Quarterly, 27, 634-652.

Bass, B. M. (1985). Leadership: Good, better, best. Organizational Dynamics, 13, 26-40.

Bass, B. M. (2000). The future of leadership in learning organizations. Journal of Leadership Studies, 7, 18-40.

Bass, B. M., \& Avolio, B. J. (1990). Developing transformational leadership: 1992 and beyond. Journal of European Industrial Training, 14, 21-27.

Bedi, A., Alpaslan, C. M., \& Green, S. (2016). A meta-analytic review of ethical leadership outcomes and moderators. Journal of Business Ethics, 139, 517-536.

Bernerth, J. B., Armenakis, A. A., Feild, H. S., Giles, W. F., \& Walker, H. J. (2007). Leadermember social exchange (LMSX): Development and validation of a scale. Journal of Organizational Behavior, 28, 979-1003.

Blau, P. M. (1964). Exchange and power in social life. Transaction Publishers.

Brower, H. H., Schoorman, F. D., \& Tan, H. H. (2000). A model of relational leadership: The integration of trust and leader-member exchange. The Leadership Quarterly, 11, 227250. 
Brown, M. E., Treviño, L. K., \& Harrison, D. A. (2005). Ethical leadership: A social learning perspective for construct development and testing. Organizational Behavior and Human Decision Processes, 97, 117-134.

Chan, S. C., \& Mak, W. M. (2014). The impact of servant leadership and subordinates' organizational tenure on trust in leader and attitudes. Personnel Review, 43, 272-287.

Chen, X. P., Eberly, M. B., Chiang, T. J., Farh, J. L., \& Cheng, B. S. (2014). Affective trust in Chinese leaders linking paternalistic leadership to employee performance. Journal of Management, 40, 796-819.

Chen, Z., Lam, W., \& Zhong, J. A. (2007). Leader-member exchange and member performance: A new look at individual-level negative feedback-seeking behavior and team-level empowerment climate. Journal of Applied Psychology, 92, 202-212.

Cheng, B. S., Chou, L. F., Wu, T. Y., Huang, M. P., \& Farh, J. L. (2004). Paternalistic leadership and subordinate responses: Establishing a leadership model in Chinese organizations. Asian Journal of Social Psychology, 7, 89-117.

Chiang, C. F., \& Lin, M. Y. (2016). Motivating organizational commitment in hotels: The relationship between leaders and employees. Journal of Human Resources in Hospitality \& Tourism, 15, 462-484.

Cohen, J., \& Cohen, P. (1983). Applied multiple regression/ correlation analysis for the behavioral sciences (2nd ed.). Hillsdale, NJ: Erlbaum

Colquitt, J. A., Baer, M. D., Long, D. M., \& Halvorsen-Ganepola, M. D. (2014). Scale indicators of social exchange relationships: A comparison of relative content validity. Journal of Applied Psychology, 99, 599-618. 
Colquitt, J. A., LePine, J. A., Piccolo, R. F., Zapata, C. P., \& Rich, B. L. (2012). Explaining the justice-performance relationship: Trust as exchange deepener or trust as uncertainty reducer?. Journal of Applied Psychology, 97, 1-15.

Colquitt, J. A., Scott, B. A., \& LePine, J. A. (2007). Trust, trustworthiness, and trust propensity: a meta-analytic test of their unique relationships with risk taking and job performance. Journal of Applied Psychology, 92, 909-927.

Conchie, S. M., Taylor, P. J., \& Donald, I. J. (2012). Promoting safety voice with safetyspecific transformational leadership: The mediating role of two dimensions of trust. Journal of Occupational Health Psychology, 17, 105-115.

Cropanzano, R., Anthony, E. L., Daniels, S. R., \& Hall, A. V. (2017). Social exchange theory: A critical review with theoretical remedies. Academy of Management Annals, 11, 479-516.

De Jong, B. A., Dirks, K. T., \& Gillespie, N. (2016). Trust and Team Performance: A MetaAnalysis of Main Effects, Moderators, and Covariates. Journal of Applied Psychology, 101, 1134-1150.

Den Hartog, D. N. (2015). Ethical leadership. Annual Review of Organizational Psychology and Organizational Behavior, 2, 409-434.

Den Hartog, D. N. (2018). Leadership and Trust. In R. Searle, A-M. Nienaber, \& S. B. Sitkin, (Eds.), The Routledge Companion to Trust. (pp. 455-468). New York: Routledge.

Derue, D. S., Nahrgang, J. D., Wellman, N. E. D., \& Humphrey, S. E. (2011). Trait and behavioral theories of leadership: An integration and meta-analytic test of their relative validity. Personnel Psychology, 64, 7-52.

Dietz, G., \& Den Hartog, D. N. (2006). Measuring trust inside organizations. Personnel Review, 35, 557-588. 
Dinh, J. E., Lord, R. G., Gardner, W. L., Meuser, J. D., Liden, R. C., \& Hu, J. (2014). Leadership theory and research in the new millennium: Current theoretical trends and changing perspectives. The Leadership Quarterly, 25, 36-62.

Dirks, K. T., \& Ferrin, D. L. (2002). Trust in leadership: meta-analytic findings and implications for research and practice. Journal of Applied Psychology, 87, 611-628.

Duffy, M. K., Ganster, D. C., \& Pagon, M. (2002). Social undermining in the workplace. Academy of Management Journal, 45, 331-351.

Dulebohn, J. H., Bommer, W. H., Liden, R. C., Brouer, R. L., \& Ferris, G. R. (2012). A metaanalysis of antecedents and consequences of leader-member exchange: Integrating the past with an eye toward the future. Journal of Management, 38, 1715-1759.

Edelman Public Relations (2016). 2016 Annual Edelman Trust Barometer.

Emerson, R. M. (1962). Power-dependence relations. American Sociological Review, 31-41.

Farh, J. L., \& Cheng, B. S. 2000. A cultural analysis of paternalistic leadership in Chinese organizations. In J. T. Li, A. S. Tsui, \& E. Weldon (Eds.), Management and organizations in the Chinese context, (pp: 84-127). London: MacMillan

Ferrin, D. L., Bligh, M. C., \& Kohles, J. C. (2008). It takes two to tango: An interdependence analysis of the spiraling of perceived trustworthiness and cooperation in interpersonal and intergroup relationships. Organizational Behavior and Human Decision Processes, 107, 161-178.

Ferris, G. R., Liden, R. C., Munyon, T. P., Summers, J. K., Basik, K. J., \& Buckley, M. R. (2009). Relationships at Work: Toward a Multidimensional Conceptualization of Dyadic Work Relationships. Journal of Management, 35, 1379-1403. 
Fulmer, C. A., \& Gelfand, M. J. (2012). At what level (and in whom) we trust: Trust across multiple organizational levels. Journal of Management, 38, 1167-1230.

Graen, G. B., \& Uhl-Bien, M. (1995). Relationship-based approach to leadership: Development of leader-member exchange (LMX) theory of leadership over 25 years: Applying a multi-level multi-domain perspective. The Leadership Quarterly, 6, 219247.

Gu, Q., Tang, T. L. P., \& Jiang, W. (2015). Does moral leadership enhance employee creativity? Employee identification with leader and leader-member exchange (LMX) in the Chinese context. Journal of Business Ethics, 126, 513-529.

Hale, J. R., \& Fields, D. L. (2007). Exploring servant leadership across cultures: A study of followers in Ghana and the USA. Leadership, 3, 397-417.

Halbesleben, J. R., \& Wheeler, A. R. (2015). To invest or not? The role of coworker support and trust in daily reciprocal gain spirals of helping behavior. Journal of Management, 41, 1628-1650.

Hiller, N. J., Sin, H. P., Ponnapalli, A. R., \& Ozgen, S. (2019). Benevolence and authority as WEIRDly unfamiliar: A multi-language meta-analysis of paternalistic leadership behaviors from 152 studies. The Leadership Quarterly, 30, 165-184.

Hoch, J. E., Bommer, W. H., Dulebohn, J. H., \& Wu, D. (2018). Do ethical, authentic, and servant leadership explain variance above and beyond transformational leadership? A meta-analysis. Journal of Management, 44, 501-529.

Hoyt, C. L., \& Blascovich, J. (2003). Transformational and transactional leadership in virtual and physical environments. Small Group Research, 34, 678-715.

Huang, X., Iun, J., Liu, A., \& Gong, Y. (2010). Does participative leadership enhance work performance by inducing empowerment or trust? The differential effects on 
managerial and non-managerial subordinates. Journal of Organizational Behavior, 31, 122-143.

Hughes, D. J., Lee, A., Tian, A. W., Newman, A., \& Legood, A. (2018). Leadership, creativity, and innovation: A critical review and practical recommendations. The Leadership Quarterly, 29, 549-569.

Hunter, S. T., Bedell-Avers, K. E., \& Mumford, M. D. (2007). The typical leadership study: Assumptions, implications, and potential remedies. The Leadership Quarterly, 18, 435-446.

Hunter, J. E., \& Schmidt, F. L. (2015). Methods of meta-analysis: Correcting error and bias in research findings (3rd Ed.). Newbury Park, CA: Sage.

Ilies, R., Morgeson, F. P., \& Nahrgang, J. D. (2005). Authentic leadership and eudaemonic well-being: Understanding leader-follower outcomes. The Leadership Quarterly, 16, 373-394.

Ilies, R., Nahrgang, J. D., \& Morgeson, F. P. (2007). Leader-member exchange and citizenship behaviors: A meta-analysis. Journal of Applied Psychology, 92, 269-277.

Johnson, J. W. (2000). A heuristic method for estimating the relative weight of predictor variables in multiple regression. Multivariate Behavioral Research, 35, 1-19.

Johnson, J. W., \& LeBreton, J. M. (2004). History and use of relative importance indices in organizational research. Organizational Research Methods, 7, 238-257.

Jung, D. I., \& Avolio, B. J. (2000). Opening the black box: An experimental investigation of the mediating effects of trust and value congruence on transformational and transactional leadership. Journal of Organizational Behavior, 21, 949-964. 
Kelloway, E. K., Turner, N., Barling, J., \& Loughlin, C. (2012). Transformational leadership and employee psychological well-being: The mediating role of employee trust in leadership. Work \& Stress, 26, 39-55.

Kirkman, B. L., \& Rosen, B. (1999). Beyond self-management: Antecedents and consequences of team empowerment. Academy of Management Journal, 42, 58-74.

Kirkpatrick, S. A., \& Locke, E. A. (1996). Direct and indirect effects of three core charismatic leadership components on performance and attitudes. Journal of Applied Psychology, 81, 36-51.

Konczak, L. J., Stelly, D. J., \& Trusty, M. L. (2000). Defining and measuring empowering leader behaviors: Development of an upward feedback instrument. Educational and Psychological Measurement, 60, 301-313.

Konovsky, M. A., \& Pugh, S. D. (1994). Citizenship behavior and social exchange. Academy of Management Journal, 37, 656-669.

Korsgaard, A. M., Brodt, E. S, \& Whitener, M.E. (2002). Trust in the face of conflict: The role of managerial trustworthy behavior and organizational context. Journal of Applied Psychology, 87, 312-319.

Korsgaard, M. A., Brower, H. H., \& Lester, S. W. (2015). It isn't always mutual: A critical review of dyadic trust. Journal of Management, 41, 47-70.

Kramer, R. M., \& Lewicki, R. J. (2010). Repairing and enhancing trust: Approaches to reducing organizational trust deficits. Academy of Management Annals, 4, 245-277.

Kurtessis, J. N., Eisenberger, R., Ford, M. T., Buffardi, L. C., Stewart, K. A., \& Adis, C. S. (2017). Perceived organizational support: A meta-analytic evaluation of organizational support theory. Journal of Management, 43, 1854-1884. 
Lapidot, Y., Kark, R., \& Shamir, B. (2007). The impact of situational vulnerability on the development and erosion of followers' trust in their leader. The Leadership Quarterly, 18, 16-34.

LeBreton, J. M., \& Tonidandel, S. (2008). Multivariate relative importance: Extending relative weight analysis to multivariate criterion spaces. Journal of Applied Psychology, 93, 329-345.

Lee, A., Legood, A., Hughes, D., Tian, A. W., Newman, A., \& Knight, C. (2020). Leadership, creativity and innovation: a meta-analytic review. European Journal of Work and Organizational Psychology, 29, 1-35.

Lee, A., Lyubovnikova, J., Tian, A. W., \& Knight, C. (2020). Servant leadership: A metaanalytic examination of incremental contribution, moderation, and mediation. Journal of Occupational and Organizational Psychology, 93, 1-44.

Lee, A., Martin, R., Thomas, G., Guillaume, Y., \& Maio, G. R. (2015). Conceptualizing leadership perceptions as attitudes: Using attitude theory to further understand the leadership process. The Leadership Quarterly, 26, 910-934.

Lee, A., Thomas, G., Martin, R., Guillaume, Y., \& Marstand, A. F. (2019). Beyond relationship quality: The role of leader-member exchange importance in leaderfollower dyads. Journal of Occupational and Organizational Psychology, 92, 736763.

Lee, A., Willis, S., \& Tian, A. W. (2018). Empowering leadership: A meta-analytic examination of incremental contribution, mediation, and moderation. Journal of Organizational Behavior, 39, 306-325. 
Lemoine, G. J., Hartnell, C. A., \& Leroy, H. (2019). Taking stock of moral approaches to leadership: An integrative review of ethical, authentic, and servant leadership. Academy of Management Annals, 13, 148-187.

Lian, H., Ferris, D. L., \& Brown, D. J. (2012). Does taking the good with the bad make things worse? How abusive supervision and leader-member exchange interact to impact need satisfaction and organizational deviance. Organizational Behavior and Human Decision Processes, 117, 41-52.

Liden, R. C., \& Graen, G. (1980). Generalizability of the vertical dyad linkage model of leadership. Academy of Management Journal, 23, 451-465.

Liden, R. C., \& Maslyn, J. M. (1998). Multidimensionality of leader-member exchange: An empirical assessment through scale development. Journal of Management, 24, 43-72.

Liden, R. C., Wayne, S. J., Meuser, J. D., Hu, J., Wu, J., \& Liao, C. (2015). Servant leadership: Validation of a short form of the SL-28. The Leadership Quarterly, 26, 254-269.

Liden, R. C., Wayne, S. J., Zhao, H., \& Henderson, D. (2008). Servant leadership: Development of a multidimensional measure and multi-level assessment. The Leadership Quarterly, 19, 161-177.

Lin, C. P., Lin, M. Z., \& Li, Y. B. (2015). An empirical study on the effect of paternalistic leadership on employees' voice behaviors-the intermediary role of psychological empowerment. Journal of Interdisciplinary Mathematics, 18, 789-810.

Martin, R., Guillaume, Y., Thomas, G., Lee, A., \& Epitropaki, O. (2016). Leader-member exchange (LMX) and performance: A meta-analytic review. Personnel Psychology, 69, 67-121. 
Mayer, R. C., Davis, J. H., \& Schoorman, F. D. (1995). An integrative model of organizational trust. Academy of Management Review, 20, 709-734.

Mayer, R. C., \& Gavin, M. B. (2005). Trust in management and performance: Who minds the shop while the employees watch the boss?. Academy of Management Journal, 48, 874-888.

McAllister, D. J. (1995). Affect-and cognition-based trust as foundations for interpersonal cooperation in organizations. Academy of Management Journal, 38, 24-59.

McEvily, B., \& Tortoriello, M. (2011). Measuring trust in organizational research: Review and recommendations. Journal of Trust Research, 1, 23-63.

Miao, Q., Newman, A and Huang, X. (2014). The impact of participative leadership on job performance and organizational citizenship behavior: Distinguishing between the mediating effects of affective and cognitive trust. International Journal of Human Resource Management, 25(20): 2796-2810.

Miao, Q., Newman, A., Schwarz, G., \& Xu, L. (2014). Servant leadership, trust, and the organizational commitment of public sector employees in China. Public Administration, 92, 727-743.

Newman, A., Kiazad, K., Miao, Q., \& Cooper, B. (2014). Examining the cognitive and affective trust-based mechanisms underlying the relationship between ethical leadership and organizational citizenship: a case of the head leading the heart?. Journal of Business Ethics, 123, 113-123.

Ng, T. W. (2017). Transformational leadership and performance outcomes: Analyses of multiple mediation pathways. The Leadership Quarterly, 28, 385-417.

Ng, T. W., \& Feldman, D. C. (2015). Ethical leadership: Meta-analytic evidence of criterionrelated and incremental validity. Journal of Applied Psychology, 100, 948-965. 
Nohe, C., \& Hertel, G. (2017). Transformational leadership and organizational citizenship behavior: A meta-analytic test of underlying mechanisms. Frontiers in Psychology, 8, 1364.

Norman, S. M., Avolio, B. J., \& Luthans, F. (2010). The impact of positivity and transparency on trust in leaders and their perceived effectiveness. The Leadership Quarterly, 21, 350-364.

Phong, L. B., Hui, L., \& Son, T. T. (2018). How leadership and trust in leaders foster employees' behavior toward knowledge sharing. Social Behavior and Personality: An International Journal, 46, 705-720.

Piccolo, R. F., Bono, J. E., Heinitz, K., Rowold, J., Duehr, E., \& Judge, T. A. (2012). The relative impact of complementary leader behaviors: Which matter most?. The Leadership Quarterly, 23, 567-581.

Pillai, R., Schriesheim, C. A., \& Williams, E. S. (1999). Fairness perceptions and trust as mediators for transformational and transactional leadership: A two-sample study. Journal of Management, 25, 897-933.

Podsakoff, P. M., MacKenzie, S. B., Lee, J. Y., \& Podsakoff, N. P. (2003). Common method biases in behavioral research: a critical review of the literature and recommended remedies. Journal of Applied Psychology, 88, 879-903.

Podsakoff, P. M., MacKenzie, S. B., Moorman, R. H., \& Fetter, R. (1990). Transformational leader behaviors and their effects on followers' trust in leader, satisfaction, and organizational citizenship behaviors. The Leadership Quarterly, 1, 107-142.

Rousseau, D. M., Sitkin, S. B., Burt, R. S., \& Camerer, C. (1998). Not so different after all: A cross-discipline view of trust. Academy of Management Review, 23, 393-404. 
Rubin, R. S., Bommer, W. H., \& Bachrach, D. G. (2010). Operant leadership and employee citizenship: A question of trust?. The Leadership Quarterly, 21, 400-408.

Scandura, T. A., \& Pellegrini, E. K. (2008). Trust and leader-member exchange: A closer look at relational vulnerability. Journal of Leadership \& Organizational Studies, 15, 101-110.

Schaubroeck, J., Lam, S. S., \& Peng, A. C. (2011). Cognition-based and affect-based trust as mediators of leader behavior influences on team performance. Journal of Applied Psychology, 96(4), $863-871$.

Schyns, B., \& Schilling, J. (2013). How bad are the effects of bad leaders? A meta-analysis of destructive leadership and its outcomes. The Leadership Quarterly, 24, 138-158.

Seppälä, T., Lipponen, J., Pirttila-Backman, A. M., \& Lipsanen, J. (2011). Reciprocity of trust in the supervisor-subordinate relationship: The mediating role of autonomy and the sense of power. European Journal of Work and Organizational Psychology, 20, $755-778$.

Shamir, B., \& Lapidot, Y. (2003). Trust in organizational superiors: Systemic and collective considerations. Organization Studies, 24, 463-491.

Tepper, B. J. (2000). Consequences of abusive supervision. Academy of Management Journal, 43, 178-190.

Tepper, B. J. (2007). Abusive supervision in work organizations: Review, synthesis, and research agenda. Journal of Management, 33, 261-289.

Tepper, B. J., Simon, L., \& Park, H. M. (2017). Abusive supervision. Annual Review of Organizational Psychology and Organizational Behavior, 4, 123-152. 
Tonidandel, S., \& LeBreton, J. M. (2011). Relative importance analysis: A useful supplement to regression analysis. Journal of Business and Psychology, 26, 1-9.

van der Werff, L., \& Buckley, F. (2017). Getting to know you: A longitudinal examination of trust cues and trust development during socialization. Journal of Management, 43, $742-770$.

van der Werff, L., Legood, A., Buckley, F., Weibel, A., \& de Cremer, D. (2019). Trust motivation: The self-regulatory processes underlying trust decisions. Organizational Psychology Review, 9, 99-123.

van Knippenberg, D. (2018). Reconsidering Affect-Based Trust: A new research agenda. In R. Searle, A-M. Nienaber, \& S. B. Sitkin, (Eds.), The Routledge Companion to Trust. (pp. 3-13). New York: Routledge.

van Knippenberg, D., \& Sitkin, S. B. (2013). A critical assessment of charismaticTransformational leadership research: Back to the drawing board? The Academy of Management Annals, 7, 1-60.

Van Quaquebeke, N., \& Felps, W. (2018). Respectful inquiry: A motivational account of leading through asking questions and listening. Academy of Management Review, 43, $5-27$.

Viswesvaran, C., \& Ones, D. S. (1995). Theory testing: Combining psychometric metaanalysis and structural equations modeling. Personnel Psychology, 48, 865-885.

Walumbwa, F. O., Avolio, B. J., Gardner, W. L., Wernsing, T. S., \& Peterson, S. J. (2008). Authentic leadership: Development and validation of a theory-based measure. Journal of Management, 34, 89-126.

Wang, H., Law, K. S., Hackett, R. D., Wang, D., \& Chen, Z. X. (2005). Leader-member exchange as a mediator of the relationship between transformational leadership and 
followers' performance and organizational citizenship behavior. Academy of Management Journal, 48, 420-432.

Williams, M. (2001). In whom we trust: Group membership as an affective context for trust development. Academy of Management Review, 26, 377-396.

Wu, M., Huang, X., Li, C., \& Liu, W. (2012). Perceived interactional justice and trust-insupervisor as mediators for paternalistic leadership. Management and Organization Review, 8, 97-121.

Xu, A. J., Loi, R., \& Lam, L. W. (2015). The bad boss takes it all: How abusive supervision and leader-member exchange interact to influence employee silence. The Leadership Quarterly, 26, 763-774.

Yang, J and Mossholder, K. W. (2010). Examining the effects of trust in leaders: A basesand-foci approach. Leadership Quarterly, 21(1): 50-63.

Yang, J., Mossholder, K. W and Peng, T. K. (2009). Supervisory procedural justice effects: The mediating roles of cognitive and affective trust. Leadership Quarterly, 20: 143-154. Zhang, X., \& Zhou, J. (2014). Empowering leadership, uncertainty avoidance, trust, and employee creativity: Interaction effects and a mediating mechanism. Organizational Behavior and Human Decision Processes, 124, 150-164.

Zhu, Y., \& Akhtar, S. (2014a). The mediating effects of cognition-based trust and affectbased trust in transformational leadership's dual processes: evidence from China. The International Journal of Human Resource Management, 25, 2755-2771.

Zhu, Y., \& Akhtar, S. (2014b). How transformational leadership influences follower helping behavior: The role of trust and prosocial motivation. Journal of Organizational Behavior, 35, 373-392. 
Zhu, W., Newman, A., Miao, Q., \& Hooke, A. (2013). Revisiting the mediating role of trust in transformational leadership effects: Do different types of trust make a difference?. The Leadership Quarterly, 24, 94-105. 
Table 1

List of Leadership Styles, Definitions and Source

\begin{tabular}{ll}
\hline Leadership Style & Definition \\
\hline Authentic & $\begin{array}{l}\text { A pattern of leader behaviour that draws upon } \\
\text { and promotes both positive psychological } \\
\text { capacities and a positive ethical climate, to } \\
\text { foster greater self-awareness, an internalised } \\
\text { moral perspective, balanced processing of } \\
\text { information, and relational transparency on the } \\
\text { part of leaders working with followers, fostering } \\
\text { positive self- development. }\end{array}$
\end{tabular}

Servant

Leadership

An understanding and practice of leadership that places the good of those led over the selfinterest of the leader, emphasizing leader behaviors that focus on follower development, and de-emphasizing glorification of the leader.

Ethical Leadership The demonstration of normatively appropriate conduct through personal actions and interpersonal relationships, and the promotion of such conduct to followers through two-way communication, reinforcement, and decisionmaking.

\section{Theorised link to trust}

Authentic leaders build benevolence and integrity by encouraging open communication, engaging their followers, sharing critical information, and sharing their perceptions and feelings. This form of individualised concern and respect should build trust through positive SEs. Further, high moral standards, integrity, and honesty, should fosters positive expectations among followers, enhancing their levels of trust.

Servant leaders are concerned with the betterment of their followers.

For instance, a servant leader encourages followers to plan for future opportunities, is willing to delegate responsibilities and share authority with followers. When followers feel that they are receiving such benefits from the servant leader, they should be motivated to trust their leader.

Ethical leaders' fair treatment, consistent behaviour, and clear communication likely result in trust from followers. Such behaviours signal SE behaviours that are likely to promote positive interactions and reciprocity from followers. Further it is argued that ethical leaders are likely to inspire trust in followers as ethical behaviour signals these leaders take an interest in issues beyond themselves, rather than being egotistical.
Source

Walumbwa,

Avolio, Gardner,

Wernsing \&

Peterson (2008)

Hale \& Fields

(2007)

Brown et al. 
Paternalistic

Leadership

Empowering

Leadership

Abusive

Supervision

Transformational

Leadership
A style that combines strong discipline and authority with fatherly benevolence. The most common measure treats paternalistic as three dimensional, consisting of authority,

benevolence, and morality (Cheng, Chou, \& Farh, 2000; Cheng, Chou,

Wu, Huang, \& Farh, 2004). In this conceptualisation, authoritarianism is a strong form of authority which reflects the leader's unquestioned authority and control over employees, benevolence reflects the leader's care and concern for the well-being of employees (and their families), and morality reflects the leader's selflessness, moral character, and integrity.

Leader behaviour directed at individuals or teams that involves delegating authority to employees, promoting their self-directed and autonomous decision making, coaching, sharing information, and asking for input.

Defined as the extent to which leaders engage in ongoing displays of verbal and non-verbal hostility (Tepper, 2000). Examples of abusive supervision include humiliating employees in public, mocking, belittlement, rudeness, breaking promises and other inappropriate behaviours.

An ongoing process, whereby "leaders and followers raise one another to higher levels of morality and motivation beyond self-interest to
Benevolent leaders show genuine care for their followers and do things to support them. These positive exchanges should strengthen the bonds of trust with followers. Similarly, when leaders act in line with high moral standards and integrity, followers are more likely to be view them as role models, thus developing trust with their leaders.

Conversely, the monitoring and controlling behaviours associated with authoritarian leadership is likely to spur negative SE, which results in subordinates' negative reciprocity and distrust.

Empowering behaviours such as providing discretion and latitude over decision making constitute positive exchange behaviours. Furthermore, empowering ones followers makes a leader vulnerable and demonstrates confidence; key features of trust (Zhang \& Zhou, 2014).

The reciprocation of positive exchanges with a leader builds trust. In contrast, if a leader engages in abusive behaviour, it will inevitably reduce followers' trust in leaders. Thus, in accordance with SET, trust decreases over time as a result of unfavourable exchanges with a leader. Abusive supervision represents unpleasant behaviours that can be predicted to contribute to feelings of distrust of the leader (Tepper, 2007).

Transformational leaders are theorised to increase followers' trust levels by showing concern for their needs, honouring agreements, demonstrating the capability and persistence to
Farh \& Cheng,

Chen, Lam, \&

Zhong, (2007);

Kirkman \& Rosen,

(1999); Konczak,

Stelly, \& Trusty, (2000)

\section{Schyns \&}

Schilling (2013)

Avolio \& Bass (1991) 
serve collective interests. The dimensions of transformational leadership conceptualised by Bass (1985) include idealised influence (whereby the leader serves as a role model and followers idealize and emulate the behaviours of their trusted leader), inspirational motivation (whereby the leader articulates a clear vision to followers and provides them with symbols and emotional appeals focused on goal achievement), intellectual stimulation (whereby the leader promotes creativity among followers through encouraging them to change ways of thinking and doing), and individualised consideration (whereby the leader addresses needs of followers individually and delegates assignments to them to provide opportunities for learning).

Transactional Leadership
Transactional leadership is based on an economic exchange process in which the leader provides rewards in return for the subordinate's effort and performance. The dimensions of transactional leadership model include contingent reward (followers and leaders have a positively reinforcing interaction) and management-by-exception (the leader intervenes only when things go wrong). achieve their vision, and through the encouragement of followers to make their own decisions. Such actions represent positive SEs and over time transformational leaders respected and trusted by their followers (e.g., Bass and Avolio, 1990)
Transactional leadership, in the form of contingent reward, involves the provision of rewards in exchange for followers' meeting performance expectations. By using contingent rewards, transactional leaders tend to acquire trust from followers through a reliable execution of largely economic exchanges (Bass, 1985). Thus, based on SET, as long as the transactional leader consistently recognises followers'

performance and provides appropriate rewards, he or she is likely to be trusted for being consistent and showing integrity.

Management-by-exception entails a focus on corrective action and (preventing) mistakes and indiscretions in follower behaviour. Although management-by-exception is commonly referred to as transactional it is less exchange based than contingent reward. It is perhaps best described as performance monitoring. This form of leadership is less
Avolio \& Bass (1991) 
likely to build trust as followers may see performance

monitoring as abusive and controlling in some situations

(Kelloway et al., 2005). 
Table 2

Meta-Analytic Results for the Relationship Between Leadership Styles and Overall, Cognitive and Affective Trust in the Leader

\begin{tabular}{|c|c|c|c|c|c|c|c|c|c|c|}
\hline \multirow[b]{2}{*}{ Variable } & \multicolumn{8}{|c|}{$90 \% \mathrm{CI}$} & \multicolumn{2}{|c|}{$80 \% \mathrm{CV}$} \\
\hline & $k$ & $N$ & $r$ & Lower & Upper & $\rho$ & $S D_{\rho}$ & $\% \mathrm{VE}$ & Lower & Upper \\
\hline \multicolumn{11}{|l|}{ Trust in the Leader } \\
\hline Transformational & 59 & 279182 & .64 & .63 & .65 & .67 & .03 & 6.33 & .63 & .72 \\
\hline Transactional & 18 & 268148 & .63 & .60 & .65 & .65 & .05 & 1.15 & .59 & .72 \\
\hline Servant & 13 & 3100 & .56 & .51 & .62 & .64 & .11 & 18.41 & .51 & .78 \\
\hline Authentic & 20 & 4530 & .56 & .49 & .63 & .64 & .18 & 7.26 & .40 & .87 \\
\hline Ethical & 19 & 4883 & .58 & .50 & .66 & .65 & .23 & 4.06 & .36 & .94 \\
\hline Empowering & 13 & 3699 & .56 & .50 & .61 & .63 & .12 & 13.73 & .48 & .77 \\
\hline Paternalistic - Moral & 5 & 1793 & .64 & .57 & .70 & .74 & .09 & 15.14 & .63 & .85 \\
\hline Paternalistic - Benevolence & 5 & 1793 & 67 & .65 & .69 & .77 & .00 & 99.15 & .76 & .77 \\
\hline Paternalistic - Authoritarian & 5 & 1793 & -.41 & -.46 & -.35 & -.49 & .06 & 45.94 & -.56 & -.41 \\
\hline Abusive & 8 & 3058 & -.42 & -.48 & -.36 & -.48 & .08 & 28.04 & -.57 & -.38 \\
\hline
\end{tabular}

\section{Cognitive Trust in the Leader}

$\begin{array}{lcccccccccc}\text { Transformational } & 11 & 2857 & .61 & .57 & .66 & .70 & .09 & 18.31 & .58 & .83 \\ \text { Servant } & 6 & 1211 & .52 & .40 & .64 & .58 & .15 & 12.05 & .39 & .78\end{array}$




$\begin{array}{lcccccccccc}\text { Authentic } & 3 & 597 & .63 & .55 & .71 & .68 & .07 & 28.84 & .59 & .78 \\ \text { Ethical } & 3 & 369 & .60 & .53 & .67 & .67 & .06 & 57.12 & .60 & .74 \\ \text { Abusive } & 3 & 936 & -.35 & -.41 & -.29 & -.41 & .04 & 68.77 & -.46 & -.36 \\ \text { Empowering } & 4 & 1057 & .55 & .47 & .64 & .64 & .10 & 19.40 & .51 & .77\end{array}$

\section{Affective Trust in the Leader}

\begin{tabular}{|c|c|c|c|c|c|c|c|c|c|c|}
\hline Transformational & 14 & 3583 & .55 & .48 & .62 & .63 & .17 & 8.28 & .42 & .84 \\
\hline Servant & 5 & 923 & .58 & .47 & .70 & .69 & .12 & 17.79 & .53 & .84 \\
\hline Authentic & 4 & 723 & .57 & .45 & .69 & .62 & .15 & 11.74 & .43 & .81 \\
\hline Ethical & 5 & 672 & .67 & .63 & .72 & .74 & .05 & 56.13 & .68 & .80 \\
\hline Abusive & 3 & 918 & -.39 & -.48 & -.31 & -.46 & .08 & 35.23 & -.56 & -.36 \\
\hline Empowering & 7 & 2113 & .54 & .46 & .61 & .61 & .12 & 12.78 & .46 & .77 \\
\hline
\end{tabular}

Notes. Results are corrected for criterion and predictor unreliability. $\mathrm{k}=$ number of correlations; $\mathrm{N}=$ number of respondents; $\mathrm{r}=$ sample weighted mean correlation; $\rho=$ corrected population correlation; $\mathrm{SD} \rho=$ standard deviation of the corrected population correlation; $\% \mathrm{VE}=$ percentage of variance attributed to sampling error in corrected population correlation; $90 \% \mathrm{CI}=90 \%$ confidence interval around the sample weighted mean correlation; $80 \% \mathrm{CV}=80 \%$ credibility interval around the corrected population correlation. 
Table 3

Meta-Analytic Results for the Relationship Between the Dimensions of the Full-Range Leadership Model and Overall Trust in the Leader

\begin{tabular}{|c|c|c|c|c|c|c|c|c|c|c|}
\hline \multirow[b]{2}{*}{ Variable } & \multirow[b]{2}{*}{$k$} & \multirow[b]{2}{*}{$N$} & \multirow[b]{2}{*}{$r$} & \multicolumn{2}{|c|}{$90 \% \mathrm{CI}$} & \multirow[b]{2}{*}{$\rho$} & \multirow[b]{2}{*}{$S D_{\rho}$} & \multirow[b]{2}{*}{$\% \mathrm{VE}$} & \multicolumn{2}{|c|}{$80 \% \mathrm{CV}$} \\
\hline & & & & Lower & Upper & & & & Lower & Upper \\
\hline \multicolumn{11}{|l|}{ Transformational } \\
\hline Inspirational Motivation & 4 & 945 & .57 & .50 & .64 & .65 & .04 & 61.01 & .59 & .70 \\
\hline Intellectual Stimulation & 5 & 1422 & .64 & .51 & .78 & .73 & .20 & 3.90 & .48 & .98 \\
\hline Idealised Influence & 6 & 1235 & .65 & .59 & .71 & .75 & .08 & 26.12 & .65 & .85 \\
\hline Individualised Consideration & 4 & 945 & .55 & .39 & .70 & .66 & .19 & 7.76 & .42 & .90 \\
\hline \multicolumn{11}{|l|}{ Transactional } \\
\hline Contingent Reward & 8 & 2316 & .52 & .43 & .62 & 63 & .16 & 8.67 & .42 & .84 \\
\hline Management-by-exception & 4 & 1009 & -.07 & -.39 & .25 & -.08 & .47 & 2.58 & -.68 & .52 \\
\hline Laissez Faire/Passive & 5 & 1134 & -.49 & -.58 & -.39 & -.60 & .13 & 18.91 & -.76 & -.43 \\
\hline
\end{tabular}

Notes. Results are corrected for criterion and predictor unreliability. $\mathrm{k}=$ number of correlations; $\mathrm{N}=$ number of respondents; $\mathrm{r}=$ sample weighted mean correlation; $\rho=$ corrected population correlation; SD $\rho=$ standard deviation of the corrected population correlation; $\%$ VE $=$ percentage of variance attributed to sampling error in corrected population correlation; $90 \% \mathrm{CI}=90 \%$ confidence interval around the sample weighted mean correlation; $80 \% \mathrm{CV}=80 \%$ credibility interval around the corrected population correlation. 
Running head: TRUST IN LEADERSHIP META-

ANALYSIS

Table 4

Relative Weights Analysis Comparing the Relative Importance of Leaderships styles on Overall, Cognitive and Affective Trust in the Leader

\begin{tabular}{lccc}
\hline Leadership Style & Trust in the Leader & Cognitive Trust & Affective Trust \\
\hline Servant & 35.86 & 36.14 & 56.86 \\
Transformational & 41.50 & 63.86 & 43.14 \\
Contingent Reward & 22.64 & - & - \\
\hline Authentic & 35.34 & 47.47 & 48.78 \\
Transformational & 32.76 & 52.53 & 51.22 \\
Contingent Reward & 31.90 & - & - \\
\hline Ethical & 35.07 & 46.29 & 63.17 \\
Transformational & 37.42 & 53.71 & 36.83 \\
Contingent Reward & 27.53 & - & - \\
\hline Empowering & 35.45 & 42.60 & 47.31 \\
Transformational & 33.25 & 57.40 & 52.69 \\
Contingent Reward & 31.29 & - & - \\
\hline Moral & 28.53 & N/A & N/A \\
Benevolent & 38.27 & N/A & N/A N/A \\
Authoritarian & 16.61 & N/A & N/A \\
Transformational & 16.59 & 34.92 & 21.98 \\
\hline Abusive & 21.83 & 11.91 & 78.02 \\
Transformational & 39.01 & 82.82 & - \\
Contingent Reward & 39.16 & - & 32.78 \\
\hline Servant & 31.39 & 22.15 & 14.04 \\
Ethical & 23.98 & 31.02 & \\
Authentic & 24.49 & & \\
Abusive & 20.14 & & N/A \\
\hline
\end{tabular}


Table 5

Incremental Variance Explained by Leadership Styles

\begin{tabular}{|c|c|c|c|c|c|c|}
\hline \multirow[b]{2}{*}{ Leadership Style } & \multicolumn{2}{|c|}{ Overall Trust in the Leader } & \multicolumn{2}{|c|}{ Cognitive Trust } & \multicolumn{2}{|c|}{ Affective Trust } \\
\hline & Effect & $\Delta \mathbf{R}^{2}$ & Effect & $\Delta \mathbf{R}^{2}$ & Effect & $\Delta \mathbf{R}^{2}$ \\
\hline Transformational & $.46^{* *}$ & Baseline $=.47$ & $.70 * *$ & Baseline $=.49$ & $.63 * *$ & Baseline $=.40$ \\
\hline Contingent Reward & $.26 * *$ & & & & & \\
\hline Servant & $.60 * *$ & $.12(20 \%)$ & $.30 * *$ & $.06(11 \%)$ & $.50 * *$ & $.18(31 \%)$ \\
\hline Transformational & $.66 * *$ & & $.55 * *$ & & $.37 * *$ & \\
\hline Contingent Reward & $-.38 * *$ & & & & & \\
\hline Authentic & $.32 * *$ & $.05(10 \%)$ & $.35 * *$ & $.06(11 \%)$ & $.40 * *$ & $.11(22 \%)$ \\
\hline Transformational & $.21 * *$ & & $.43 * *$ & & $.42 * *$ & \\
\hline Contingent Reward & $.27 * *$ & & & & & \\
\hline Ethical & $.32 * *$ & $.05(10 \%)$ & $.35 * *$ & $.06(11 \%)$ & $.59 * *$ & $.17(30 \%)$ \\
\hline Transformational & $.37 * *$ & & $.45 * *$ & & $.22 * *$ & \\
\hline Contingent Reward & $.09 * *$ & & & & & \\
\hline Empowering & $.33 * *$ & $.06(11 \%)$ & $.31 * *$ & $.05(9 \%)$ & $.34 * *$ & $.06(13 \%)$ \\
\hline Transformational & $.25 * *$ & & $.49 * *$ & & $.40 * *$ & \\
\hline Contingent Reward & $.26 * *$ & & & & & \\
\hline Abusive & $-.20 * *$ & $.03(6 \%)$ & -.03 & $.00(0 \%)$ & $-.16 * *$ & $.01(2 \%)$ \\
\hline Transformational & $.30 * *$ & & $.69 * *$ & & $.54 * *$ & \\
\hline Contingent Reward & $.32 * *$ & & & & & \\
\hline Moral & $.41 * *$ & $.34(58 \%)$ & & & & \\
\hline Benevolent & $.58 * *$ & & & & & \\
\hline Authoritarian & $-.30 * *$ & & & & & \\
\hline Transformational & $-.13 * *$ & & & & & \\
\hline
\end{tabular}


Table 6

Meta-Analytic Results for the Relationship Between Trust in the Leader and Performance and OCB

\begin{tabular}{|c|c|c|c|c|c|c|c|c|c|c|}
\hline \multirow[b]{2}{*}{ Variable } & \multicolumn{8}{|c|}{$90 \% \mathrm{CI}$} & \multicolumn{2}{|c|}{$80 \% \mathrm{CV}$} \\
\hline & $k$ & $N$ & $r$ & Lower & Upper & $\rho$ & $S D_{\rho}$ & $\% \mathrm{VE}$ & Lower & Upper \\
\hline \multicolumn{11}{|l|}{ Performance } \\
\hline Trust in the Leader & 53 & 12237 & .26 & .24 & .29 & .30 & .11 & 28.22 & .16 & .45 \\
\hline Cognitive Trust in the Leader & 11 & 2366 & .17 & .14 & .21 & .20 & .05 & 68.94 & .14 & .27 \\
\hline Affective Trust in the Leader & 15 & 4177 & .22 & .20 & .25 & .26 & .00 & 100.00 & .26 & .26 \\
\hline \multicolumn{11}{|l|}{ OCB } \\
\hline Trust in the Leader & 39 & 10615 & .30 & .27 & .32 & .34 & .08 & 36.47 & .23 & .44 \\
\hline Cognitive Trust in the Leader & 9 & 2180 & .22 & .18 & .27 & .25 & .05 & 65.42 & .19 & .32 \\
\hline Affective Trust in the Leader & 12 & 3740 & .30 & .26 & .33 & .34 & .06 & 48.52 & .26 & .42 \\
\hline \multicolumn{11}{|c|}{ Cognitive Trust - Affective Trust } \\
\hline Cognitive - Affective & 27 & 6474 & .66 & .62 & .70 & .77 & .11 & 13.03 & .63 & .90 \\
\hline
\end{tabular}

Notes. Results are corrected for criterion and predictor unreliability. $\mathrm{k}=$ number of correlations; $\mathrm{N}=$ number of respondents; $\mathrm{r}=$ sample weighted mean correlation; $\rho=$ corrected population correlation; SD $\rho=$ standard deviation of the corrected population correlation; $\%$ VE = percentage of variance attributed to sampling error in corrected population correlation; $90 \% \mathrm{CI}=90 \%$ confidence interval around the sample weighted mean correlation; $80 \% \mathrm{CV}=80 \%$ credibility interval around the corrected population correlation. 
Table 7

Regression Analysis Examining the Incremental Predictive Validity of Cognitive and Affective Trust in the Leader on Performance and $O C B$

\begin{tabular}{lllll}
\hline & \multicolumn{2}{c}{ Performance } & \multicolumn{2}{c}{ OCB } \\
Trust & Effect & $\boldsymbol{\Delta} \mathbf{R}^{\mathbf{2}}$ & Effect & $\boldsymbol{\Delta} \mathbf{R}^{\mathbf{2}}$ \\
Base & & & & \\
\hline Cognitive & $.20^{* *}$ & Baseline & $.25 * *$ & Baseline \\
& & $=.04$ & & $=.06$ \\
& & & & \\
Affective & $.26 * *$ & .03 & $.38^{* *}$ & .06 \\
& & $(43 \%)$ & & $(50 \%)$ \\
Cognitive & .00 & & -.05 & \\
\hline Notes: $* p<.05 . * * p<.01$ & &
\end{tabular}

Notes: $* p<.05 . * * p<.01$ 
Table 8

Mediator Analyses for Leadership Styles on Performance and OCB via Trust in the Leader and LMX

\begin{tabular}{|c|c|c|c|c|c|c|c|c|c|c|}
\hline \multirow{2}{*}{$\begin{array}{c}\text { Leadership } \\
\text { Variable }\end{array}$} & \multirow[t]{2}{*}{ Outcome } & \multirow[t]{2}{*}{ Mediator } & \multirow[t]{2}{*}{$\mathbf{a}$} & \multirow[t]{2}{*}{ b } & \multirow[t]{2}{*}{ ab } & \multicolumn{2}{|c|}{$95 \% \mathrm{CI}$} & \multirow[t]{2}{*}{ c' $^{\prime}$} & \multirow[t]{2}{*}{ c } & \multirow{2}{*}{$\begin{array}{l}\% \text { indirect } \\
\text { effect via } \\
\text { trust }\end{array}$} \\
\hline & & & & & & Lower & Upper & & & \\
\hline \multirow{4}{*}{$\mathrm{TL}$} & \multirow[t]{2}{*}{ Performance } & Trust & $.67 * *$ & $.18 * *$ & $.12 * *$ & .10 & .14 & $.08 * *$ & $.27 * *$ & \multirow{2}{*}{$62+\%$} \\
\hline & & LMX & $.73 * *$ & $.10 * *$ & $.07 * *$ & .05 & .10 & $.08 * *$ & $.27 * *$ & \\
\hline & \multirow[t]{2}{*}{ OCB } & Trust & $.67 * *$ & $.25 * *$ & $.17 * *$ & .14 & .19 & -.02 & $.26 * *$ & \multirow{2}{*}{$60+\%$} \\
\hline & & LMX & $.73 * *$ & $.15^{* *}$ & $.11 * *$ & .08 & .14 & -.02 & $.26 * *$ & \\
\hline \multirow{4}{*}{$\mathrm{CR}$} & \multirow[t]{2}{*}{ Performance } & Trust & $.63 * *$ & $.22 * *$ & $.14 * *$ & .12 & .16 & $-.07 *$ & $.20 * *$ & \multirow{2}{*}{$52 \%$} \\
\hline & & LMX & $.73 * *$ & $.18 * *$ & $.13 * *$ & .10 & .16 & $-.07 *$ & $.20 * *$ & \\
\hline & \multirow[t]{2}{*}{ OCB } & Trust & $.63 * *$ & $.28 * *$ & $.18 * *$ & .15 & .20 & $-.15 * *$ & $.34 * *$ & \multirow{2}{*}{$51 \%$} \\
\hline & & LMX & $.73 * *$ & $.23 * *$ & $.17 * *$ & .14 & .20 & $-.15 * *$ & $.34 * *$ & \\
\hline \multirow{4}{*}{ SL } & \multirow[t]{2}{*}{ Performance } & Trust & $.64 * *$ & $.19 * *$ & $.12 * *$ & .10 & .14 & .04 & $.24 * *$ & \multirow{2}{*}{$61^{+\%}$} \\
\hline & & LMX & $.62 * *$ & $.12 * *$ & $.08 * *$ & .06 & .10 & .04 & $.24 * *$ & \\
\hline & \multirow[t]{2}{*}{ OCB } & Trust & $.64 * *$ & $.15 * *$ & $.10 * *$ & .08 & .12 & $.22 * *$ & $.36 * *$ & \multirow{2}{*}{$69+\%$} \\
\hline & & LMX & $.62 * *$ & $.07 * *$ & $.04 * *$ & .02 & .06 & $.22 * *$ & $.36 * *$ & \\
\hline \multirow{4}{*}{$\mathrm{AL}$} & \multirow[t]{2}{*}{ Performance } & Trust & $.64 * *$ & $.26 * *$ & $.17 * *$ & .15 & .19 & $-.16 * *$ & $.14 * *$ & \multirow{2}{*}{$56 \%$} \\
\hline & & LMX & $.65^{* *}$ & $.20 * *$ & $.13 * *$ & .11 & .16 & $-.16 * *$ & $.14 * *$ & \\
\hline & \multirow[t]{2}{*}{ OCB } & Trust & $.64 * *$ & $.18 * *$ & $.12 * *$ & .09 & .14 & $.16^{* *}$ & $.33 * *$ & \multirow{2}{*}{$69+\%$} \\
\hline & & LMX & $.65 * *$ & $.08 * *$ & $.05 * *$ & .03 & .07 & $.16^{* *}$ & $.33 * *$ & \\
\hline EL & Performance & Trust & $.65 * *$ & $.21 * *$ & $.14 * *$ & .11 & .16 & -.01 & $.21 * *$ & $62^{+\%}$ \\
\hline
\end{tabular}




\begin{tabular}{|c|c|c|c|c|c|c|c|c|c|c|}
\hline & & LMX & $.60 * *$ & $.14 * *$ & $.09 * *$ & .07 & .11 & -.01 & $.21 * *$ & \\
\hline & \multirow[t]{2}{*}{ OCB } & Trust & $.65 * *$ & $.24 * *$ & $.16^{* *}$ & .14 & .18 & -.01 & $.24 * *$ & \multirow{2}{*}{$64^{+} \%$} \\
\hline & & LMX & $.60 * *$ & $.15 * *$ & $.09 * *$ & .07 & .11 & -.01 & $.24 * *$ & \\
\hline \multirow{4}{*}{ EMP } & \multirow[t]{2}{*}{ Performance } & Trust & $.63 * *$ & $.24 * *$ & $.15 * *$ & .13 & .17 & $-.16 * *$ & $.17 * *$ & \multirow{2}{*}{$45 \%$} \\
\hline & & LMX & $.76 * *$ & $.24 * *$ & $.18 * *$ & .15 & .21 & $-.16 * *$ & $.17 * *$ & \\
\hline & \multirow[t]{2}{*}{ OCB } & Trust & $.63 * *$ & $.22 * *$ & $.14 * *$ & .12 & .16 & $.10 * *$ & $.30 * *$ & \multirow{2}{*}{$68 \%$} \\
\hline & & LMX & $.76 * *$ & $.10 * *$ & $.06 * *$ & .03 & .09 & $.10 * *$ & $.30 * *$ & \\
\hline \multirow{4}{*}{ AS } & \multirow[t]{2}{*}{ Performance } & Trust & $-.48 * *$ & $.20 * *$ & $-.10 * *$ & -.11 & -.08 & -.03 & $-.19 * *$ & \multirow{2}{*}{$58 \%$} \\
\hline & & LMX & $-.54 * *$ & $.13 * *$ & $-.07 * *$ & -.09 & -.05 & -.03 & $-.19 * *$ & \\
\hline & \multirow[t]{2}{*}{ OCB } & Trust & $-.48 * *$ & $.23 * *$ & $-.11 * *$ & -.12 & -.09 & $-.07 * *$ & $-.24 * *$ & \multirow{2}{*}{$63^{+\%}$} \\
\hline & & LMX & $-.54 * *$ & $.12 * *$ & $-.06 * *$ & -.08 & -.05 & $-.07 * *$ & $-.24 * *$ & \\
\hline \multirow{4}{*}{ PL-M } & \multirow[t]{2}{*}{ Performance } & Trust & $.35^{* *}$ & $.24 * *$ & $.08 * *$ & .06 & .11 & -.03 & $.13 * *$ & \multirow{2}{*}{$54 \%$} \\
\hline & & LMX & $.40 * *$ & $.19 * *$ & $.07 * *$ & .05 & .10 & -.03 & $.13 * *$ & \\
\hline & \multirow[t]{2}{*}{ OCB } & Trust & $.35 * *$ & .03 & .01 & -.01 & .04 & $.18 * *$ & $.22 * *$ & \multirow{2}{*}{$29^{+} \%$} \\
\hline & & LMX & $.40 * *$ & $.07 *$ & $.03 *$ & .01 & .05 & $.18 * *$ & $.22 * *$ & \\
\hline \multirow{4}{*}{ PL-B } & \multirow[t]{2}{*}{ Performance } & Trust & $.52 * *$ & $.24 * *$ & $.12 * *$ & .09 & .16 & $-.08 *$ & $.14 * *$ & \multirow{2}{*}{$57 \%$} \\
\hline & & LMX & $.50 * *$ & $.19 * *$ & $.09 * *$ & .07 & .12 & $-.08 *$ & $.14 * *$ & \\
\hline & \multirow[t]{2}{*}{$\mathrm{OCB}$} & Trust & $.52 * *$ & .03 & .02 & -.02 & .05 & $.09 * *$ & $.15 * *$ & \multirow{2}{*}{$32^{+} \%$} \\
\hline & & LMX & $.50 * *$ & $.07 *$ & $.03 *$ & .01 & .06 & $.09 * *$ & $.15 * *$ & \\
\hline \multirow{4}{*}{ PL-A } & \multirow[t]{2}{*}{ Performance } & Trust & $-.29 * *$ & $.24 * *$ & $-.07 * *$ & -.09 & -.05 & -.03 & $-.11 * *$ & \multirow{2}{*}{$93+\%$} \\
\hline & & LMX & $-.03 *$ & $.19 * *$ & -.01 & -.01 & -.00 & -.03 & $-.11 * *$ & \\
\hline & \multirow[t]{2}{*}{ OCB } & Trust & $-.29 * *$ & .03 & -.01 & -.03 & .01 & $-.12 * *$ & $-.13 * *$ & \multirow{2}{*}{$82 \%$} \\
\hline & & LMX & $-.03 *$ & $.07 *$ & -.00 & -.00 & .00 & $-.12 * *$ & $-.13 * *$ & \\
\hline
\end{tabular}


Note. Standardized coefficients are presented. $a=$ first stage mediation effect; $b=$ second stage mediation effect; $a b=$ indirect effect; $c^{\prime}=$ direct effect; $\mathrm{c}=$ overall effect $* \mathrm{p}<.05 . * * \mathrm{p}<.01 .+$ indicate that indirect effects are significantly different as indicated by non-overlapping

$T L=$ Transformational Leadership; $C R=$ Contingent Reward $; S L=$ Servant Leadership; $A L=$ Authentic Leadership; EL = Ethical Leadership; $E M P=$ Empowering Leadership; $A S=$ Abusive Supervision; $P L-M=$ Paternalistic Leadership - Morality; PL-B =Paternalistic Leadership -

Benevolence; $P L-A=$ Paternalistic Leadership - Authoritarian. 
Table 9

Mediator Analyses for Leadership Styles on Performance and OCB via Cognitive and Affective Trust and LMX

\begin{tabular}{|c|c|c|c|c|c|c|c|c|c|c|}
\hline \multirow[t]{2}{*}{$\begin{array}{c}\text { Leadership } \\
\text { Style }\end{array}$} & \multirow[t]{2}{*}{ Outcome } & \multirow[t]{2}{*}{ Mediator } & \multirow[t]{2}{*}{$\mathbf{a}$} & \multirow[t]{2}{*}{$\mathbf{b}$} & & \multicolumn{2}{|c|}{$\begin{array}{c}\text { 95\% CI for indirect } \\
\text { effect }\end{array}$} & \multirow[t]{2}{*}{ c' } & \multirow[t]{2}{*}{ c } & \multirow[t]{2}{*}{$\begin{array}{c}\% \text { indirect via } \\
\text { mediator }\end{array}$} \\
\hline & & & & & & Lower & Upper & & & \\
\hline \multirow{6}{*}{$\mathrm{TL}$} & Performance & Affective Trust & $.63 * *$ & $.16^{* *}$ & $.10 * *$ & .07 & .13 & $.16^{* *}$ & $.27 * *$ & $92 \%$ \\
\hline & & Cognitive Trust & $.70 * *$ & $-.12 * *$ & $-.08 * *$ & -.12 & -.05 & $.16^{* *}$ & $.27 * *$ & $-78 \%$ \\
\hline & & LMX & $.73 * *$ & $.12 * *$ & $.09 * *$ & .05 & .13 & $.16^{* *}$ & $.27 * *$ & $86 \%$ \\
\hline & OCB & Affective Trust & $.63 * *$ & $.29 * *$ & $.18 * *$ & .15 & .21 & .06 & $.26 * *$ & $89 \%$ \\
\hline & & Cognitive Trust & $.70 * *$ & $-.09 * *$ & $-.06 * *$ & -.09 & -.03 & .06 & $.26 * *$ & $-30 \%$ \\
\hline & & LMX & $.73 * *$ & $.12 * *$ & $.08 * *$ & .05 & .12 & .06 & $.26 * *$ & $41 \%$ \\
\hline \multirow{6}{*}{ SL } & Performance & Affective Trust & $.69 * *$ & $.11 * *$ & $.08 * *$ & .04 & .11 & $.08 *$ & $.24 * *$ & $48 \%$ \\
\hline & & Cognitive Trust & $.58 * *$ & $-.06 *$ & $-.03 *$ & -.06 & -.01 & $.08 *$ & $.24 * *$ & $-21 \%$ \\
\hline & & LMX & $.62 * *$ & $.19 * *$ & $.12 * *$ & .09 & .14 & $.08 *$ & $.24 * *$ & $73 \%$ \\
\hline & OCB & Affective Trust & $.69 * *$ & $.18 * *$ & $.12 * *$ & .09 & .15 & $.23 * *$ & $.36 * *$ & $92 \%$ \\
\hline & & Cognitive Trust & $.58 * *$ & $-.08 * *$ & $-.05 * *$ & -.07 & -.02 & $.23 * *$ & $.36 * *$ & $-35 \%$ \\
\hline & & LMX & $.62 * *$ & $.09 * *$ & $.06 * *$ & .03 & .08 & $.23 * *$ & $.36 * *$ & $43 \%$ \\
\hline
\end{tabular}




\begin{tabular}{|c|c|c|c|c|c|c|c|c|c|c|}
\hline & Performance & Affective Trust & $.62 * *$ & $.15^{* *}$ & $.10 * *$ & .07 & .12 & $-.11 * *$ & $.14 * *$ & $38 \%$ \\
\hline & & Cognitive Trust & $.68 * *$ & -.01 & -.00 & -.04 & .03 & $-.11 * *$ & $.14 * *$ & $-1 \%$ \\
\hline \multirow[t]{4}{*}{$\mathrm{AL}$} & & LMX & $.65^{* *}$ & $.24 * *$ & $.16^{* *}$ & .13 & 19 & $-.11 * *$ & $.14 * *$ & $63 \%$ \\
\hline & OCB & Affective Trust & $.62 * *$ & $.27 * *$ & $.17 * *$ & .14 & .19 & $.22 * *$ & $.33 * *$ & $158 \%$ \\
\hline & & Cognitive Trust & $.68 * *$ & $-.16^{* *}$ & $-.11 * *$ & -.14 & -.08 & $.22 * *$ & $.33 * *$ & $-101 \%$ \\
\hline & & LMX & $.65^{* *}$ & $.07 *$ & $.05^{*}$ & .02 & .07 & $.22 * *$ & $.33 * *$ & $42 \%$ \\
\hline \multirow{6}{*}{ EL } & Performance & Affective Trust & $.74 * *$ & $.13^{* *}$ & $.10^{* *}$ & .06 & .14 & .03 & $.21 * *$ & $54 \%$ \\
\hline & & Cognitive Trust & $.67 * *$ & $-.06^{*}$ & $-.04 *$ & -.07 & -.01 & .03 & $.21 * *$ & $-21 \%$ \\
\hline & & LMX & $.60 * *$ & $.20 * *$ & $.12 * *$ & .10 & .15 & .03 & $.21 * *$ & $67 \%$ \\
\hline & OCB & Affective Trust & $.74 * *$ & $.30 * *$ & $.22 * *$ & .06 & .11 & -.03 & $.24 * *$ & $82 \%$ \\
\hline & & Cognitive Trust & $.67 * *$ & $-.06 *$ & $-.04 *$ & -.07 & -.01 & -.03 & $.24 * *$ & $-14 \%$ \\
\hline & & LMX & $.60 * *$ & $.15^{* *}$ & $.09 * *$ & .06 & .11 & -.03 & $.24 * *$ & $32 \%$ \\
\hline \multirow{4}{*}{ EMP } & Performance & Affective Trust & $.61 * *$ & $.14 * *$ & $.09 * *$ & .06 & .11 & $-.11 * *$ & $.17 * *$ & $31 \%$ \\
\hline & & Cognitive Trust & $.64 * *$ & -.02 & -.01 & -.04 & .02 & $-.11 * *$ & $.17 * *$ & $-5 \%$ \\
\hline & & LMX & $.76^{* *}$ & $.27 * *$ & $.21 * *$ & .17 & .25 & $-.11 * *$ & $.17 * *$ & $74 \%$ \\
\hline & OCB & Affective Trust & $.61 * *$ & $.29 * *$ & $.18 * *$ & .15 & .21 & $.15 * *$ & $.30 * *$ & $120 \%$ \\
\hline
\end{tabular}




\begin{tabular}{|c|c|c|c|c|c|c|c|c|c|c|}
\hline & & Cognitive Trust & $.64 * *$ & $-.10 * *$ & $-.07 * *$ & -.10 & -.04 & $.15^{* *}$ & $.30 * *$ & $-45 \%$ \\
\hline & & LMX & $.76^{* *}$ & .05 & .04 & -.00 & .08 & $.15^{* *}$ & $.30 * *$ & $25 \%$ \\
\hline \multirow{6}{*}{ AS } & Performance & Affective Trust & $-.46 * *$ & $.14 * *$ & $-.07 * *$ & -.08 & -.05 & -.05 & $-.19 * *$ & $46 \%$ \\
\hline & & Cognitive Trust & $-.41 * *$ & $-.05 *$ & $.02 *$ & .01 & .04 & -.05 & $-.19 * *$ & $-15 \%$ \\
\hline & & LMX & $-.54 * *$ & $.19 * *$ & $-.10 * *$ & -.12 & -.08 & -.05 & $-.19 * *$ & $69 \%$ \\
\hline & OCB & Affective Trust & $-.46 * *$ & $.27 * *$ & $-.13 * *$ & -.15 & -.11 & $-.08 * *$ & $-.24 * *$ & $81 \%$ \\
\hline & & Cognitive Trust & $-.41 * *$ & $-.07 * *$ & $.03 * *$ & .01 & .04 & $-.08 * *$ & $-.24 * *$ & $-17 \%$ \\
\hline & & LMX & $-.54 * *$ & $.11 * *$ & $-.06 * *$ & -.08 & -.04 & $-.08 * *$ & $-.24 * *$ & $37 \%$ \\
\hline
\end{tabular}

Note. Standardized coefficients are presented. $a=$ first stage mediation effect; $b=$ second stage mediation effect; $a b=i n d i r e c t ~ e f f e c t ; ~ c '=d i r e c t$ effect; $\mathrm{c}=$ overall effect $* \mathrm{p}<.05 . * * \mathrm{p}<.01$.

$T L=$ Transformational Leadership; $S L=$ Servant Leadership $; A L=$ Authentic Leadership $;$ EL $=$ Ethical Leadership; EMP $=$ Empowering Leadership; $A S=$ Abusive Supervision; 